University of Nebraska - Lincoln

DigitalCommons@University of Nebraska - Lincoln

1977

\title{
Three-Dimensional Crust and Mantle Structure of Kilauea Volcano, Hawaii
}

Willam L. Ellsworth

U.S. Geological Survey

Robert Y. Koyanagi

U.S. Geological Survey

Follow this and additional works at: https://digitalcommons.unl.edu/usgsstaffpub

Part of the Earth Sciences Commons

Ellsworth, Willam L. and Koyanagi, Robert Y., "Three-Dimensional Crust and Mantle Structure of Kilauea Volcano, Hawaii" (1977). USGS Staff -- Published Research. 383.

https://digitalcommons.unl.edu/usgsstaffpub/383

This Article is brought to you for free and open access by the US Geological Survey at DigitalCommons@University of Nebraska - Lincoln. It has been accepted for inclusion in USGS Staff -- Published Research by an authorized administrator of DigitalCommons@University of Nebraska - Lincoln. 


\title{
Three-Dimensional Crust and Mantle Structure of Kilauea Volcano, Hawaii
}

\author{
William L. ELLSWORTH \\ U.S. Geological Survey, Cambridge, Massachusetts 02139 \\ Department of Earth and Planetary Sciences, Massachusetts Institute of Technology \\ Cambridge, Massachusetts 02139
}

\section{ROBERT Y. KOYANAGI}

\author{
Hawaiian Volcano Observatory, U.S. Geological Survey, Hawaii National Park, Hawaii 96718
}

\begin{abstract}
Teleseismic $P$ wave arrival times recorded by a dense network of seismograph stations located on Kilauea volcano, Hawaii, are inverted to determine lateral variations in crust and upper mantle structure to a depth of $70 \mathrm{~km}$. The crustal structure is dominated by relatively high velocities within the central summit complex and along the two radial rift zones, compared with the nonrift flank of the volcano. Both the mean crustal velocity contrast between summit and nonrift flank and the distribution of velocities agree well with results from crustal refraction studies. Comparison of the velocity structure with Bouguer gravity anomalies over the volcano through a simple physical model also gives excellent agreement. Mantle structure appears to be more homogeneous than crustal structure. The root mean square velocity variation for the mantle averages only $1.5 \%$, whereas variation within the crust exceeds $4 \%$. The summit of Kilauea is underlain by normal velocity $(8.1 \mathrm{~km} / \mathrm{s})$ material within the uppermost mantle $(12-25 \mathrm{~km})$, suggesting that large magma storage reservoirs are not present at this level and that the passageways from deeper sources must be quite narrow. No evidence is found for substantial volumes of partially molten rock $(5 \%)$ within the mantle to depths of at least $40 \mathrm{~km}$. Below about $30 \mathrm{~km}$, low-velocity zones (1-2\%) underlie the summits of Kilauea and nearby Mauna Loa and extend south of Kilauea into a broad offshore zone. Correlation of volcanic tremor source locations and persistent zones of mantle earthquakes with low-velocity mantle between 27.5 - and $42.5-\mathrm{km}$ depth suggests that a laterally extensive conduit system feeds magma to the volcanic summits from sources either at comparable depth or deeper within the mantle. The center of contemporary magmatic production and/or upwelling from deeper in the mantle appears to extend well to the south of the active volcanic summits, suggesting that the Hawaiian Island chain is actively extending to the southeast.
\end{abstract}

\section{INTRODUCTION}

Three-dimensional variations in the physical properties of the lithosphere exist in virtually every tectonic region on earth, both ancient and young. Until the advent of high-speed digital computers it was impossible to study the three-dimensional structure of the earth except for a limited class of problems. Seismological studies, in particular, have been largely restricted to one-dimensional models and interpretations. Recently, Aki et al. [1977] developed an elegant method for determining laterally varying velocity structure from seismic array recordings of teleseismic body waves and applied the method to continental arrays in the United States and Norway [Aki et al., 1976; Husebye et al., 1976].

In this paper the three-dimensional velocity structure of Kilauea volcano, a young, active shield volcano on the island of Hawaii, is investigated by using the seismograph network of the Hawaiian Volcano Observatory (HVO) and the technique of Aki et al. Study by this method is attractive for several reasons. The location of Hawaii near the center of the Pacific plate places the volcano at teleseismic distances from sources distributed about the plate margin and beyond, assuring a good azimuthal distribution of sources. Dense seismograph network coverage on the volcano (Figure 1 and Table 1) provides for detailed sampling of the crust and upper mantle beneath the array along inclined teleseismic ray paths. Gradual topographic relief facilitates the use of simple corrections for the effects of station elevation.

Analysis of the deep, three-dimensional velocity structure of Kilauea is motivated by the potential for extending our knowledge of the internal structure of shield volcanoes. Fortunately,

Copyright @ 1977 by the American Geophysical Union. Paper number 7B0600. much is already known about the structure of Kilauea from over a half century of continuous geological and geophysical observations. This long history of research has led to a coherent picture of the volcanic processes and structure of Kilauea, especially those within the crust, and provides an excellent reference for the models obtained in this study.

\section{Summary of Geologic Structure}

Kilauea is now in its youthful period of activity characterized by rapid growth of its broad shield by frequent eruptions of fluid basaltic lava. Partial melting of the mantle at depths below at least $60 \mathrm{~km}$ [Eaton and Murata, 1960; Jackson and Wright. 1970] produces tholeiitic magma that ascends to within a few kilometers of the central summit of Kilauea, where it accumulates prior to eruption. There is some evidence for intermediate storage and differentiation of the magma at depths of 20-30 km [Mogi, 1958; Wright, 1971]. The spatial distribution of mantle earthquakes may outline the pathways through which magma slowly ascends to the surface [Eaton, 1962].

Most eruptive cycles commence with inflation of the shallow ( $3 \pm 1 \mathrm{~km}$ ) magma chamber underlying the central summit of the volcano. Deflation of the summit does not generally accompany extrusion of magma from vents in the summit complex but follows the forceful injection of magma into one or both of the two rift zones, which radiate outward from the summit [Eaton and Murata, 1960; Swanson et al., 1971]. The rifts themselves form within the breakaway zone of the unbuttressed, seaward mobile south flank of the volcano [Wilson. 1963; Moore and Krivoy, 1964; Fiske and Kinoshita, 1969]. Through a complex system of conduits within the rifts, copious volumes of magma are carried many kilometers from 


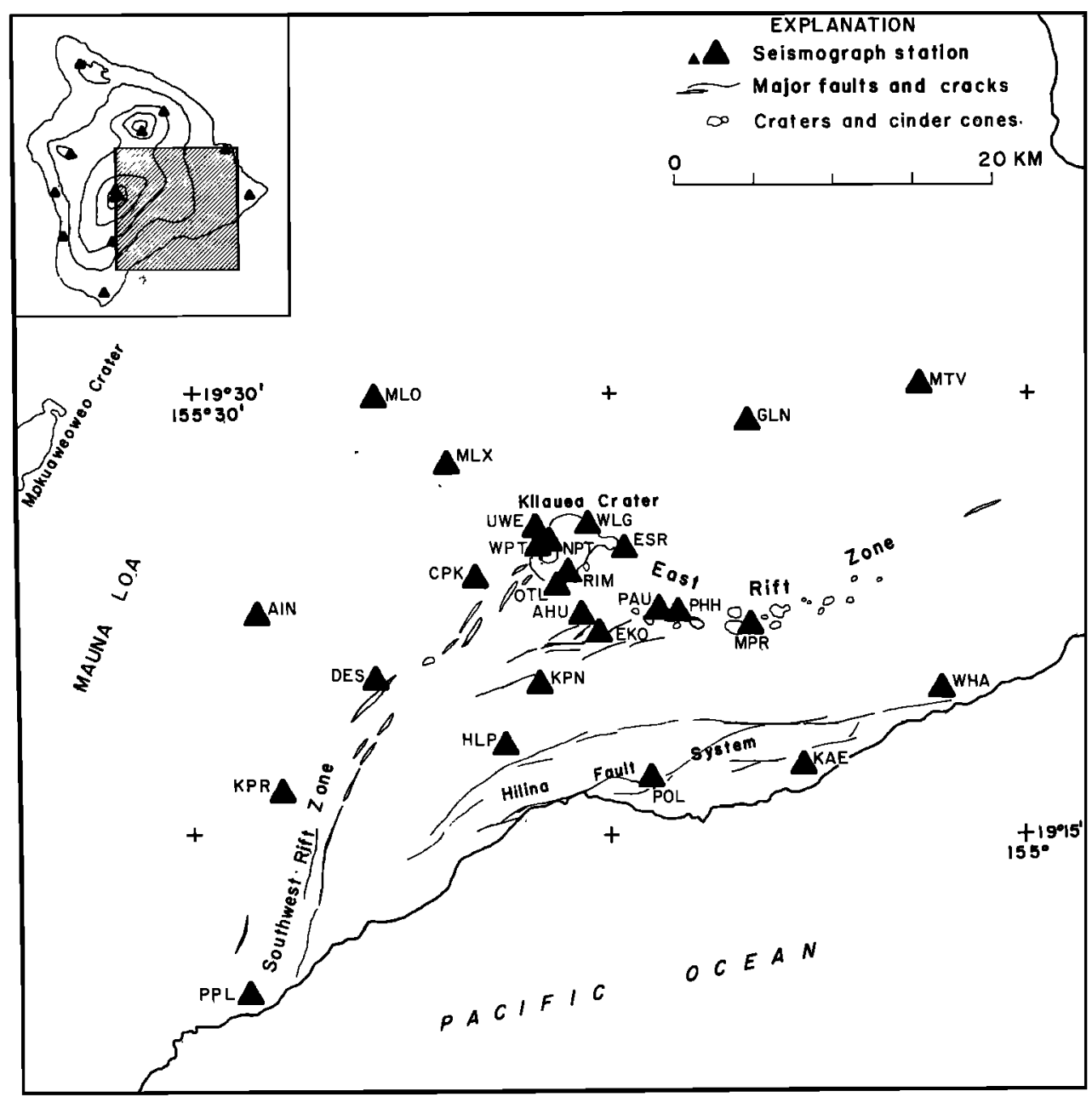

Fig. 1. Map of Kilauea volcano and surrounding region outlining area modeled for three-dimensional structure. Seismograph stations used in inversion analysis and major structural features, including summits of Kilauea and Mauna Loa and rift zones of Kilauea, are shown. Inset includes regional seismograph stations and elevation contours in kilometers.

the summit to vents from which they flow, building the broad, low-relief shield of the volcano. Both the summit and the rift zones contain denser material, on the average, than the shield areas [Kinoshita et al., 1963], owing to the presence of numerous intrusive dikes and sills.

Detailed studies of crustal velocity structure by $R$ yall and Bennett [1968] and Hill [1969] indicate significant differences in structure between rift and nonrift flanks. Mean crustal $P$ wave velocities within the summit and rifts of Kilauea are substantially higher than the average velocity of shield areas, reflecting differences in structure, as discussed above. Beneath the volcanic pile and old oceanic floor the Mohorovicic discontinuity lies at shallow depth, $12 \mathrm{~km}$ under the southeast coast of Kilauea and perhaps as shallow as $10 \mathrm{~km}$ below the summit (Figure 2; Hill [1969, Figure 11]).

Knowledge of mantle structure beneath young volcanoes on Hawaii is largely limited to inferences based upon the distribution of mantle earthquakes [Eaton, 1962; Koyanagi et al., 1975], changes in level measured over long base lines [Mogi, 1958], and comparisons with older volcanoes of the Hawaiian chain [Wright, 1971]. Concentrations of earthquakes beneath the summits of Kilauea and Mauna Loa, which extend to depths of $60 \mathrm{~km}$ or more, are believed to outline regions through which magma ascends to the summits of the two volcanoes. Zones relatively free of earthquakes between about
15 and $30 \mathrm{~km}$ below both Mauna Loa and Kilauea have led Koyanagi et al. [1975] to speculate that these earthquake-free zones delineate magma storage areas. Jackson and Wright [1970] present additional evidence for laterally varying mantle structure beneath the Hawaiian chain based upon their study of xenoliths in the Honolulu volcanic series. They conclude that the mature volcanoes are underlain by a refractory root extending to a depth of at least $100 \mathrm{~km}$ and further argue that partial melting of the mantle to produce tholeiitic magma is restricted to a relatively narrow vertical zone underlying the volcanic summits.

\section{MeTHOD OF ANALYSIS}

The modeling technique developed by $A$ ki et al. [1977] is used to estimate the three-dimensional velocity structure beneath Kilauea. In this method a finite region beneath the seismograph array is allowed laterally varying velocities, while the earth outside the modeled region is considered to have known velocity structure. Derivation of the linearized system of equations solved to obtain estimates of the lateral variations in velocity may be found in the paper by $A k i$ et al. [1977].

Briefly, velocity perturbations to the initial model are given by the solution of

$$
\mathbf{r}=\mathbf{A m}+\mathbf{e}
$$


where $r$ is a vector containing travel time residuals computed by using the starting model, $A$ is a matrix containing partial derivatives of the travel time along each ray with respect to the unknown velocity perturbations $\mathrm{m}$, and the vector e contains higher-order terms and error terms. Let

$$
A^{T} \mathbf{A}=\mathbf{G}
$$

then (1) becomes, to first order,

$$
G m=A^{T} \mathbf{r}
$$

Least squares solution of (2) fails because the symmetric semidefinite matrix $G$ contains one zero eigenvalue for each layer in the initial model [Aki et al., 1977]. Equation (2) could be solved by using the generalized inverse operator of Lanczos [1961]. However, this requires decomposition of $G$ into its eigenvalues and eigenvectors, an expensive operation because the rank of $G$ is typically $250-300$ for models considered here. Damped least squares [Levenberg, 1944] offer an attractive alternative, since they can be used to approximate the generalized inverse and require only an elimination algorithm for solution. The damped least squares solution to (2) is given by

$$
\hat{m}=(\mathrm{G}+\theta 1)^{-1} A^{T_{\mathrm{r}}}
$$

where $\hat{m}$ is an approximate solution of (1), $\theta$ is a positive constant (damping parameter), and $I$ is the identity matrix. For (3) the resolution matrix is given by

$$
R=(G+\theta 1)^{-1} G
$$

and the covariance matrix by

$$
C=\sigma_{d}^{2}(G+\theta 1)^{-1} R
$$

when errors in the data are uncorrelated and have uniform variance ${\sigma_{d}}^{2}$.

The velocity structure adopted for the inhomogeneous region as a starting model is composed of plane-parallel layers, each having a constant velocity. Each layer is subdivided into an array of right rectangular prisms for which we seek velocity perturbations $\hat{m}$. Computation of ray paths through the initial model is simplified by assigning the entire ray path in each layer to the block in which the ray spends the maximum time. Artificially introduced model boundaries corresponding to the vertical sides of the block elements are smoothed out by this approximation. Relative residual travel times $r$ are computed by subtracting the theoretical travel time from source to station from the observed travel time and then subtracting the mean residual for each event.

Successful recovery of the laterally varying structure from the data requires a cross fire of rays through the model. Azimuthally well distributed sources aid the fulfillment of this requirement. Mixing of ray paths and blocks is optimized by choosing a block size that equalizes the vertical and horizontal transit times through each element of the model. For teleseismic sources a ratio of the vertical height to the horizontal length of a model element of 2:1 is appropriate. Selection of elements with a size ratio of $1: 1$ vertically links blocks together regardless of the azimuth of approach of the teleseismic ray, degrading resolution of the model.

The mean velocity within each layer is indeterminate when relative residual travel times are used. This inherent nonuniqueness arises because changes in the mean travel time through the model cannot be separated from the origin time of the source or contributions to the travel time residuals common to all observations which arise along ray path segments lying outside of the model. Consequently, the mean velocity in each horizontal layer is held constant. Vertical smoothing of the solution; unavoidably introduced in this problem when damped least squares are used (equation (3)), presents a potential problem in interpretation [Aki et al., 1977], as the averaging kernels extend over unknowns recoverable only to within an arbitrary constant. The effect of these inherent limitations may be evaluated through study of the resolution and covariance of the solution, as discussed below.

TABLE 1. Seismograph Stations on Kilauea Volcano

\begin{tabular}{llrrr}
\hline Station & Position & Elevation, $\mathrm{m}$ & Observations & Mean Residual, s \\
\hline AIN & $19^{\circ} 22.50^{\prime} \mathrm{N}, 155^{\circ} 27.62^{\prime} \mathrm{W}$ & 1524 & 67 & 0.30 \\
AHU & $19^{\circ} 22.40^{\prime} \mathrm{N}, 155^{\circ} 15.90^{\prime} \mathrm{W}$ & 1070 & 137 & -0.10 \\
CPK & $19^{\circ} 23.70^{\prime} \mathrm{N}, 155^{\circ} 19.70^{\prime} \mathrm{W}$ & 1038 & 135 & -0.15 \\
DES & $19^{\circ} 20.20^{\prime} \mathrm{N}, 155^{\circ} 23.30^{\prime} \mathrm{W}$ & 815 & 131 & -0.09 \\
EKO & $19^{\circ} 21.80^{\prime} \mathrm{N}, 155^{\circ} 15.30^{\prime} \mathrm{W}$ & 1009 & 25 & -0.10 \\
ESR & $19^{\circ} 24.68^{\prime} \mathrm{N}, 155^{\circ} 14.33^{\prime} \mathrm{W}$ & 1177 & 73 & -0.13 \\
GLN & $19^{\circ} 29.00^{\prime} \mathrm{N}, 155^{\circ} 09.90^{\prime} \mathrm{W}$ & 900 & 9 & 0.05 \\
HLP & $19^{\circ} 17.96^{\prime} \mathrm{N}, 155^{\circ} 18.63^{\prime} \mathrm{W}$ & 707 & 88 & 0.11 \\
KAE & $19^{\circ} 17.35^{\prime} \mathrm{N}, 155^{\circ} 07.95^{\prime} \mathrm{W}$ & 37 & 43 & -12 \\
KPN & $19^{\circ} 20.10^{\prime} \mathrm{N}, 155^{\circ} 17.40^{\prime} \mathrm{W}$ & 924 & 114 & 0.01 \\
KPR & $19^{\circ} 16.40^{\prime} \mathrm{N}, 155^{\circ} 26.70^{\prime} \mathrm{W}$ & 610 & 67 & 0.06 \\
MLO & $19^{\circ} 29.80^{\prime} \mathrm{N}, 155^{\circ} 23.30^{\prime} \mathrm{W}$ & 2010 & 157 & 0.18 \\
MLX & $19^{\circ} 27.60^{\prime} \mathrm{N}, 155^{\circ} 20.70^{\prime} \mathrm{W}$ & 1475 & 153 & 0.19 \\
MPR & $19^{\circ} 22.07^{\prime} \mathrm{N}, 155^{\circ} 09.85^{\prime} \mathrm{W}$ & 881 & 114 & -0.16 \\
MTV & $19^{\circ} 30.25^{\prime} \mathrm{N}, 155^{\circ} 03.75^{\prime} \mathrm{W}$ & 409 & 114 & 0.09 \\
NPT & $19^{\circ} 24.90^{\prime} \mathrm{N}, 155^{\circ} 17.00^{\prime} \mathrm{W}$ & 1115 & 69 & -0.24 \\
OTL & $19^{\circ} 23.38^{\prime} \mathrm{N}, 155^{\circ} 16.94^{\prime} \mathrm{W}$ & 1038 & 134 & -0.20 \\
PAU & $19^{\circ} 22.62^{\prime} \mathrm{N}, 155^{\circ} 13.10^{\prime} \mathrm{W}$ & 994 & 53 & -0.14 \\
PHH & $19^{\circ} 22.45^{\prime} \mathrm{N}, 155^{\circ} 12.66^{\prime} \mathrm{W}$ & 988 & 22 & -0.09 \\
POL & $19^{\circ} 17.02^{\prime} \mathrm{N}, 155^{\circ} 13.47^{\prime} \mathrm{W}$ & 169 & 62 & 0.11 \\
PPL & $19^{\circ} 09.50^{\prime} \mathrm{N}, 155^{\circ} 27.87^{\prime} \mathrm{W}$ & 35 & 52 & -0.03 \\
RIM & $19^{\circ} 23.90^{\prime} \mathrm{N}, 155^{\circ} 16.60^{\prime} \mathrm{W}$ & 1128 & 59 & -0.08 \\
UWE & $19^{\circ} 25.40^{\prime} \mathrm{N}, 155^{\circ} 17.60^{\prime} \mathrm{W}$ & 1240 & 29 & -0.19 \\
WHA & $19^{\circ} 19.90^{\prime} \mathrm{N}, 155^{\circ} 02.92^{\prime} \mathrm{W}$ & 1067 & 0.11 \\
WLG & $19^{\circ} 25.49^{\prime} \mathrm{N}, 155^{\circ} 15.69^{\prime} \mathrm{W}$ & 1115 & -0.10 \\
WPT & $19^{\circ} 24.70^{\prime} \mathrm{N}, 155^{\circ} 17.50^{\prime} \mathrm{W}$ & 58 & -0.20 \\
\hline
\end{tabular}




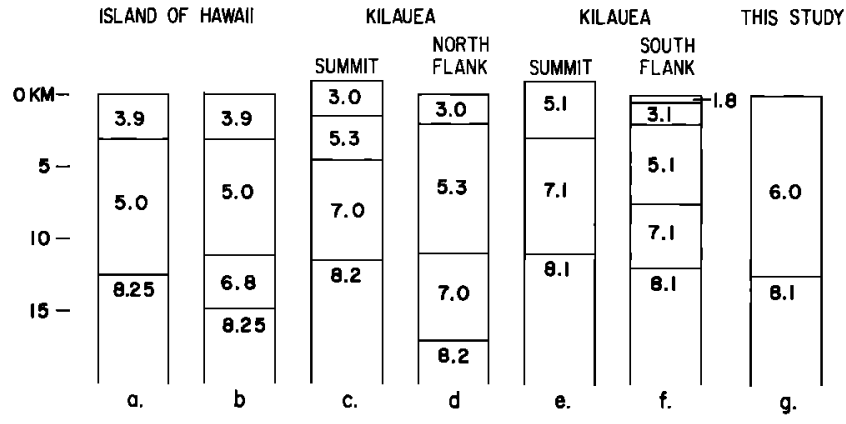

Fig. 2. Comparison of $P$ wave crustal velocity structures for Hawaii. Velocities are in kilometers per second. Sources are as follows: for $(a)$ and (b), Eaton [1962]; for (c), Kilauea summit regions, Ryall and Bennett [1968]; for $(d)$, north flank of Kilauea, Ryall and Bennett [1968]; for (e), Kilauea summit, Hill [1969]; for $(f)$, south coast of Kilauea, Hill [1969]; and for $(g)$, this study.

\section{Data Collection and Reduction}

$P$ wave arrival time readings for 108 circum-Pacific teleseisms were collected during the summer of 1975 from all available stations of the $\mathrm{HVO}$ network (Table 1) for the period 1971-1975. Events selected for analysis were chosen on the basis of their geographic location, quality of first arrival, and number of readable stations (Figure 3 ). Together with readings provided by J. Unger from Kilauea stations for 56 events, these events form an azimuthally well distributed data set at distances of $35^{\circ}-90^{\circ}$ from Hawaii.

All seismograms were written by short-period instruments of the HVO network. Each seismograph station consists of a 1$\mathrm{Hz}$ vertical seismometer, either a moving magnet model EV-17 or a moving coil model L4-C geophone, a seismic preamplifier, and a voltage-controlled oscillator used in transmission of data from remote sites to the observatory. After demodulation, 18 seismic traces are recorded in strip chart mode on 16$\mathrm{mm}$ film on one of two develocorders. Complete system magnification is approximately $10^{4}$ at $1 \mathrm{~Hz}$ [Koyanagi et al., 1974]. Local chronometer time marks appear on two additional traces, located at the top and bottom of the film. Processed films were projected onto a ground glass screen equipped with a movable hairline and viewed at a scale of $1 \mathrm{~s}$ of time to $1 \mathrm{~cm}$. Magnification of the image was corrected for each event, so that scale error was held to less than $0.1 \%$. Image distortion was also found to be less than $0.1 \%$.

The reading of arrival times involved several steps. Tracings were made of the first 5-10 s of record for 3-5 stations with representative wave forms. A prominent peak or trough appearing as early as possible in the record and common to all traces was identified and timed by using a ruler calibrated in $0.5-\mathrm{mm}$ units. Times were reported to at least the nearest 0.05 s. For most events the maxima appeared in the first 1-2 s of record. Occasionally, $p P$ phases were used. As an aid in the identification of the selected phase on stations with poorer signal to noise ratios the seismograms were visually correlated by using the tracings as overlays. Misidentification of the proper phase would introduce an easily detectable error of $2 \pi$ (approximately $1 \mathrm{~s}$ for waves measured) or multiples thereof.

Reading weights, designed to be an estimate of the confidence of the readings, were assigned to all readings. Impulsive arrivals were assigned weights according to the accuracy with which the measurement could be repeated and correspond to estimated standard errors of a single observation of $0.05 \mathrm{~s}$ for a weight of 0 and $0.1 \mathrm{~s}$ for a weight of 1 . Emergent arrivals with poorer signal to noise ratios were assigned weights of 2 and 3, corresponding to estimated uncertainties of 0.15 and $0.2 \mathrm{~s}$, respectively. Only data with weights of 2 or better were included in the analysis, for which we estimate that average error to be $0.1 \mathrm{~s}$.

The observed teleseismic $P$ waves were reduced to residual travel times by using either the Herrin or the Jeffreys-Bullen table and preliminary epicenters reported by USGS and NOAA or by finding deviations from the best-fitting plane wave. Travel times were further reduced to a reference elevation by subtracting the travel time above the datum, which is the product of the station elevation and the vertical slowness for the teleseismic ray. Relative residuals were calculated by removing the mean travel time residual from the data. This step eliminates the dependence of the residuals upon the computed origin time and total travel time. Since many readings, typically $20-30$, were used to determine the mean, the resulting estimate of the true relative travel time residual is insensitive to the particular subset of stations observing a particular event. This procedure probably adds no more than $0.1 \mathrm{~s}$ of scatter to the data and removes more than $4 \mathrm{~s}$ of scatter from the raw travel time residuals.

The arrival time data for events collected in the summer of 1975 were also reduced by using best-fitting plane waves, estimated by using the island-wide network. It was not possible to estimate plane waves for the 56 events provided by J. Unger accurately because of the limited aperture of the array formed by available stations.

The reduced travel time data contain several noteworthy features suggestive of strong lateral variations in velocity structure beneath the array. We will consider only residuals computed by using the Herrin table in this discussion, as similar results hold for the other two reductions. The mean travel time residual for each station varies rapidly from site to site within the network (Table 1), an indication of the presence of strong velocity contrasts at relatively shallow depth. Stations situated upon volcanic summits or near rift zones are early in relation to stations located on the flanks of the volcanic shield, in qualitative agreement with the crustal structure deduced by Hill [1969] from refraction profiles. Correlation of the station residuals with elevation is poor, despite over $4 \mathrm{~km}$ of vertical relief, an indication that elevation alone is not the principal factor determining the mean station residual. With attention to the presence or absence of intrusive structures near each station site, the mean residual shows improved correlation with elevation (Figure 4). Reference lines with vertical phase velocities of 5 and $6 \mathrm{~km} / \mathrm{s}$ (Figure 4) pass through sites on the flanks of the shield and through sites on summits and dike-reinforced basalt flows, respectively.

Consideration of the azimuthal variation of residual travel times also demonstrates the presence of laterally varying structures. Representative diagrams (Figure 5) indicate that the residual depends strongly upon azimuth of approach at some stations and weakly at others. Note that the scatter of the residuals within a specific azimuth range agrees with the estimated error of the arrival time readings. Correlation of the azimuthal patterns between nearby sites, as for MLO and MLX (Figure 5), implies the existence of deeper-seated heterogeneities in the mantle, since teleseismic ray paths to these stations are uncorrelated in the crust. Strong azimuthal variations in residual, such as the variation observed for station KPR (Figure 5) cannot easily be explained by the presence of shallow, subhorizontal boundaries alone. A dip angle of $30^{\circ}$ on the shallow (10-15 km) Moho explains less than half of the observed variation for this station. 


\section{INVERSION FOR THREE-DiMENSIONAL STRUCTURE}

The initial velocity structure of the crust and upper mantle beneath Kilauea consists of five homogeneous, plane-parallel layers with thickness and velocity as specified in Table 2. Each layer is subdivided into a $9 \times 9$ array of right rectangular prisms with a horizontal side length of $7.5 \mathrm{~km}$. Choice of a block size with larger cross-sectional area potentially groups together stations with widely differing mean travel time residuals in the same crustal layer block. This is undesirable, since differences in mean residual for nearby stations reflect differences in crustal structure beneath each site.

Two separate inversion studies were made by using the initial model. In the first study, $1508 P$ wave readings for the 108 teleseisms read during the summer of 1975 were inverted to investigate the dependence of the results upon the value of the damping parameter and to measure the effect of various assumptions made regarding the azimuth of approach and the $d t / d \Delta$ value for the teleseismic sources. In the second study, all $2112 P$ wave readings for the 164 source events were inverted for velocity perturbations in the 334 observed blocks.

Effect of the damping parameter. Equation (3) is a special case of the stochastic inverse of Franklin [1970] when the covariance matrices for both data and model are diagonal with constant variance. In this case the damping parameter is given by

$$
\theta=\sigma_{d}^{2} / \sigma_{m}^{2}
$$

where $\sigma_{d}$ is the standard error of the data and $\sigma_{m}$ is the root

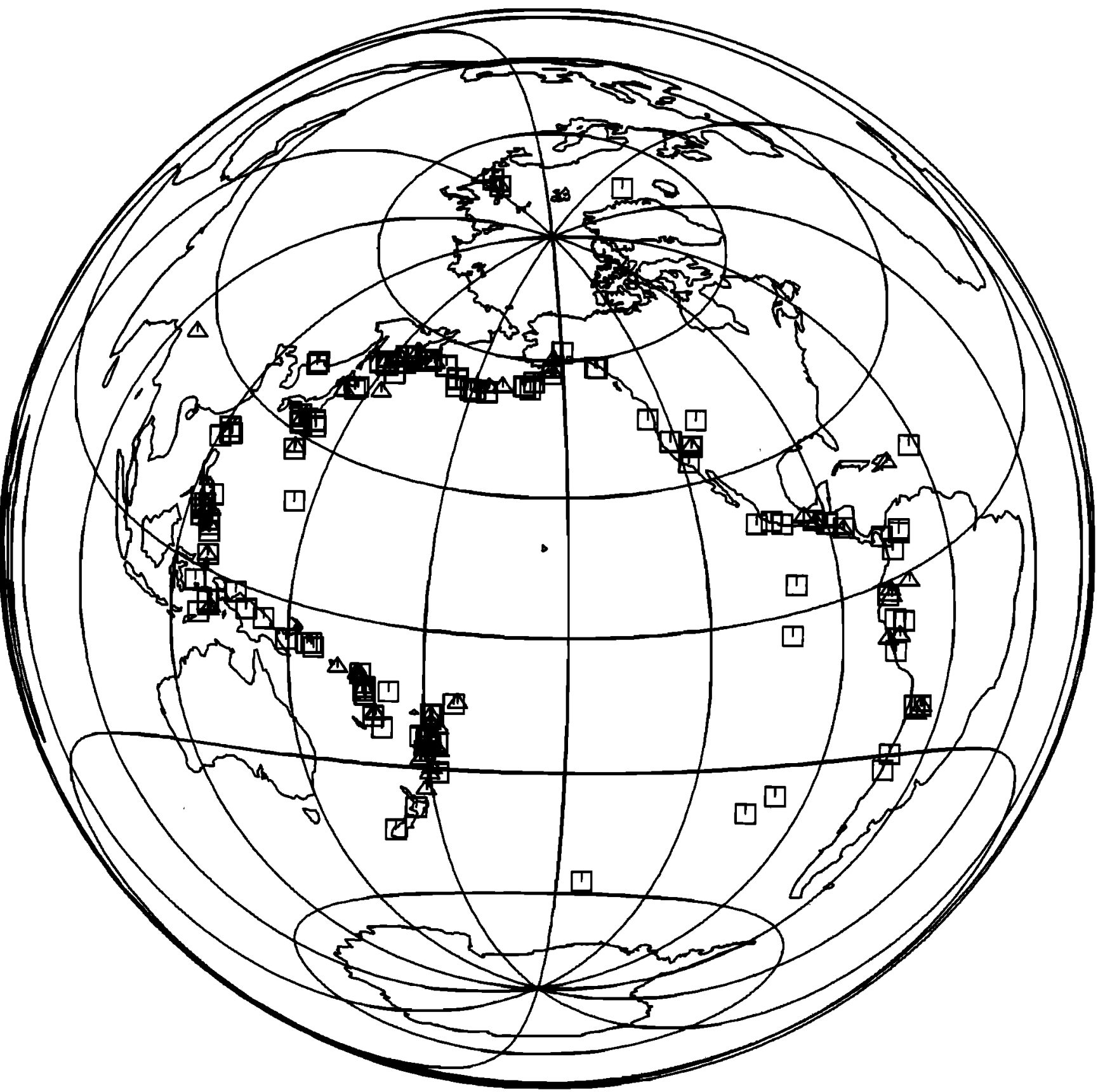

Fig. 3. Epicenters of earthquakes and explosions used as $P$ wave sources. Squares denote 108 events from first inversion study; triangles, 56 events added in second study. 


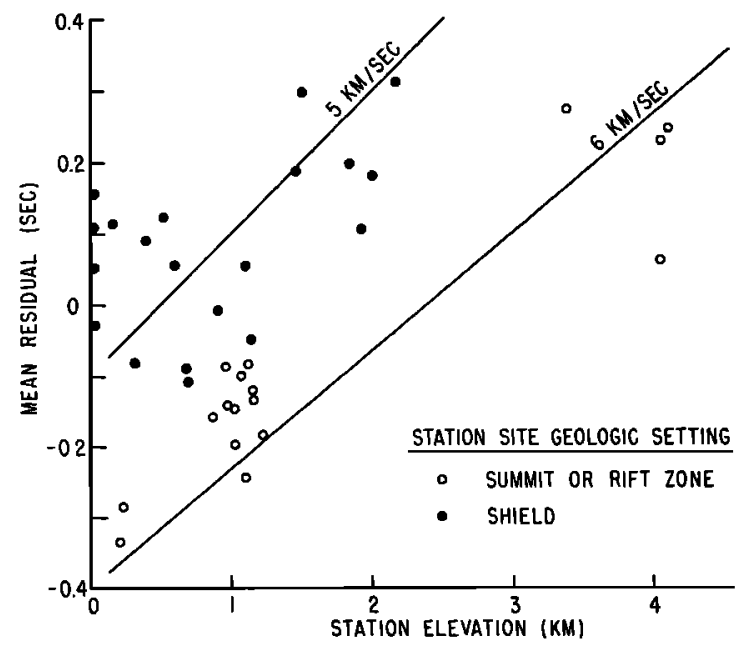

Fig. 4. Mean relative teleseismic travel time residual relative to station elevation for all Hawaii stations.

mean square variation of the true model. With $\sigma_{d}$ estimated to be $0.1 \mathrm{~s}$, solutions were computed with $\theta=10,50$, and $250 \mathrm{~s}^{2}$, corresponding to velocity fluctuations of $3 \%, 1.4 \%$, and $0.6 \%$, respectively. Eigenvalues of $G$ (equation (2)) exceed these choices of $\theta$ for $75 \%, 50 \%$, and $10 \%$ of the eigenvalues, respectively.

Model results for these choices of $\theta$, using residuals relative to the Herrin table, are shown in Figures $6 a, 6 b$, and $6 c$ for the third layer of the model. Similar results were obtained for the other layers. The broad similarity between the models is evident. Element by element comparison between these three solutions (Figures $7 a$ and $7 b$ ) shows a high degree of correlation, with a proportionality factor equal to the square root of the ratio of the damping parameters. Comparison values which lie more nearly along a line with a slope of 1 indicate that the solutions for these model elements are relatively unaffected by the change in $\theta$ (and, in fact, are well resolved in each solution). Although a variation of $\theta$ by a factor of $25 \mathrm{might}$ be expected to produce significant differences in the performance of the model, the variance of the data explained by the models
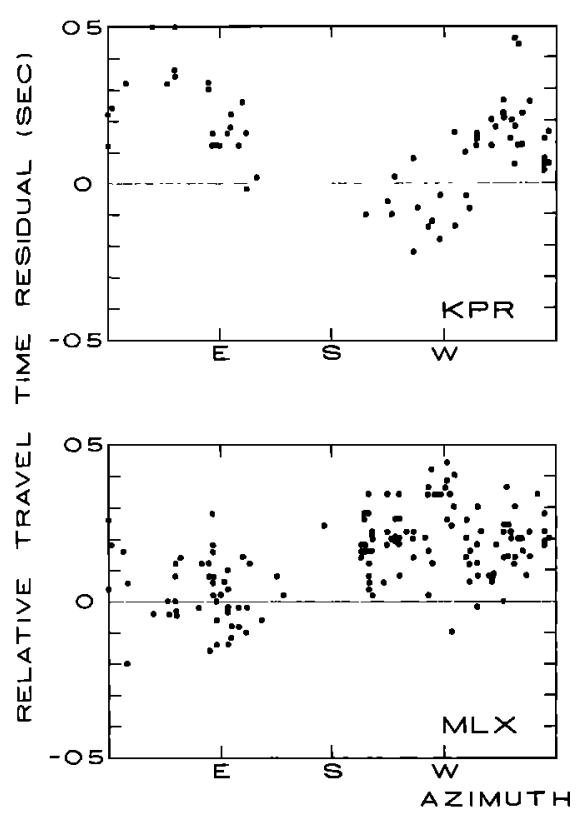

differs by only $50 \%$, suggesting that the variance improvement is largely controlled by the largest eigenvalues. The value of 50 $\mathrm{s}^{2}\left(0.005 \mathrm{~s}^{2} / \%^{2}\right)$ for $\theta$ was selected for use in the second study.

Effect of different earth models. Errors in the azimuth and slowness for each source arising from inhomogeneities outside of the model may potentially be projected into the model, which is undesirable. Comparison between solutions generated by using different estimates of the ray parameter $p$ gives an indication of the importance of these errors. Three estimates for $p$ are considered. The first two use the azimuth and distance to the source given by the hypocentral coordinates of the source and either the Herrin or the Jeffreys-Bullen table. The third estimate takes the extreme point of view of using the island-wide array to estimate $p$ by minimizing the travel time error to the wave front by using least squares. Comparison of results for layer 3 (Figures $6 a, 6 d$, and $6 e$ ) indicates that the overall anomaly pattern is not too sensitive to these fundamentally distinct estimates of $\mathbf{p}$. Detailed comparison between all model elements for these solutions (Figures $7 c$ and $7 d$ ) also shows the overall similarity between solutions. This result will not hold for a general structure investigated by using the technique, but it does hold for this particular array.

Effect of variation in block configurations. Choice of block models with differing geometries or orientations will lead, in general, to different models because of the method by which model parameters are quantized. To explore the effects of model geometry upon the solution, numerical experiments were performed comparing models with different layering and block orientation. Models with deeper layers displaced vertically by one half of a layer thickness yield solutions similar to those with layering specified by Table 2 . Additionally, neither rotation nor translation of the block model produced major changes in the overall pattern or perturbations (Figures $6 a$ and $6 f$ ).

In preparation of the cutaway model of Figure 11 the model corresponding to Figure 8 and a model with block elements diagonally displaced south and east by one half of a block width have been combined by taking four-point averages of the superimposed solutions to obtain a smoothed estimate of the lateral velocity structure. The effect of this procedure is to
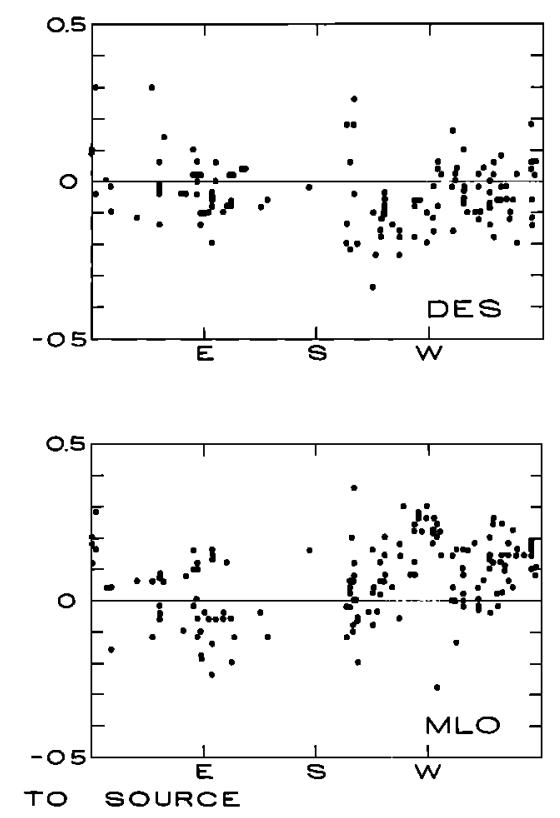

Fig. 5. Azimuthal variation of relative travel time residuals versus azimuth to source, clockwise from north. 
TABLE 2. Initial Layered Velocity Model Used in Inversion Studies

\begin{tabular}{ccccc}
\hline Layer & $\begin{array}{c}P \text { Velocity, } \\
\text { km/s }\end{array}$ & $\begin{array}{c}\text { Thickness, } \\
\text { km }\end{array}$ & $\begin{array}{c}\text { Side } \\
\text { Length, } \\
\mathrm{km}\end{array}$ & $\begin{array}{c}\text { Block } \\
\text { Length, } \\
\mathrm{km}\end{array}$ \\
\hline 1 & 6.0 & 12.5 & 67.5 & 7.5 \\
2 & 8.1 & 15.0 & 67.5 & 7.5 \\
3 & 8.1 & 15.0 & 67.5 & 7.5 \\
4 & 8.1 & 15.0 & 67.5 & 7.5 \\
5 & 8.1 & 15.0 & 67.5 & 7.5 \\
\hline
\end{tabular}

emphasize long-wavelength patterns and at the same time suppress random fluctuations and to suppress the dependence of the solution on the choice of block positions. When the reader interprets model results displayed directly as in Figure 8 or displayed as a smoothed model as in Figure 11, he should bear in mind that we cannot differentiate between lateral variations in material properties and the position of subhorizontal boundaries (e.g., depth to the Moho) as the source of the observed variations.

Resolution and errors. Stability and uniqueness of the
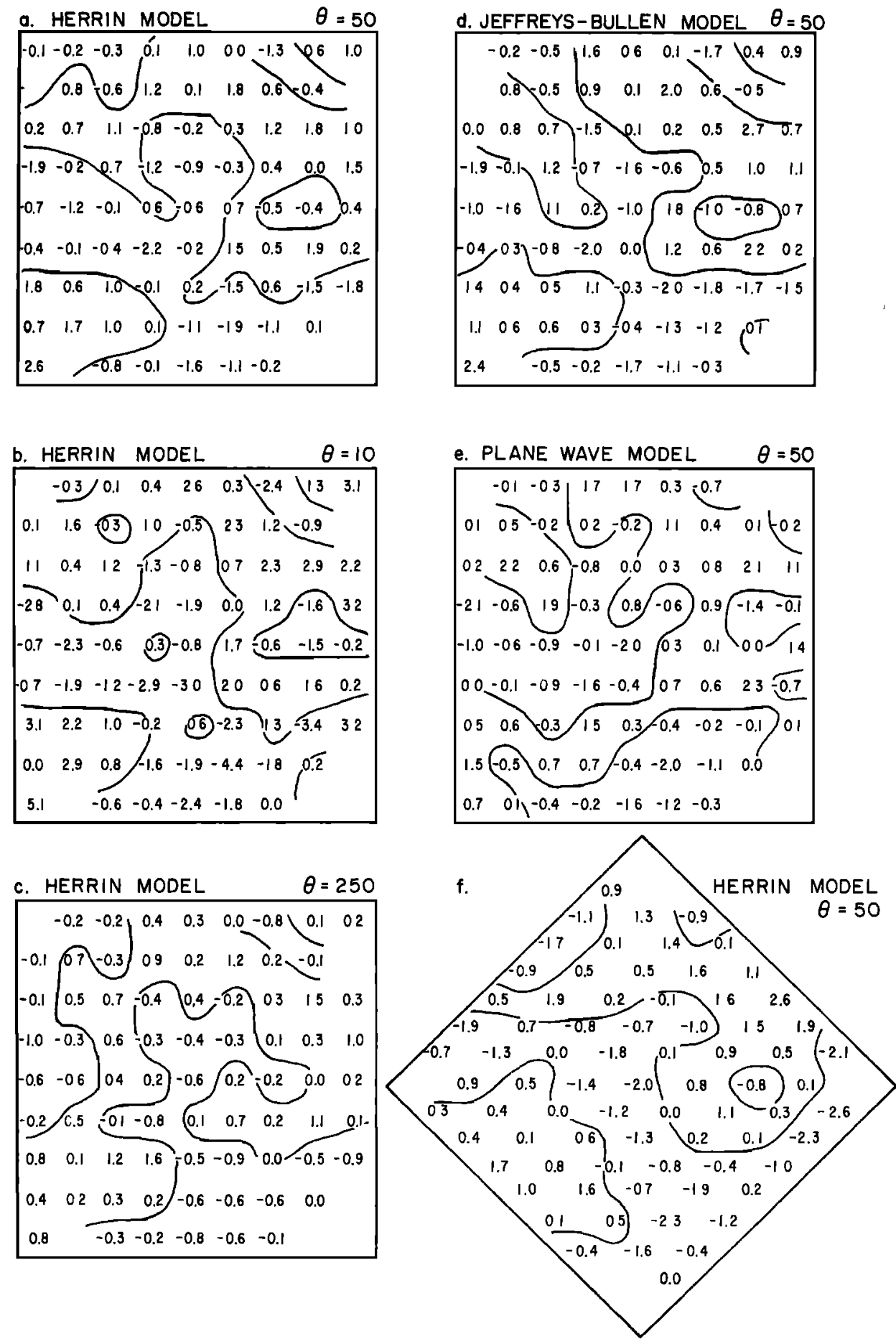

Fig. 6. Comparison of percent velocity variations for layer 3. (a) Herrin residuals, $\theta=50$. (b) Herrin residuals, $\theta=10$. (c) Herrin residuals, $\theta=250$. (d) Jeffrey-Bullen residuals, $\theta=50$. (e) Residuals to best-fitting plane waves, $\theta=50$. $(f)$ Herrin residuals, $\theta=50$, rotated $45^{\circ}$. 

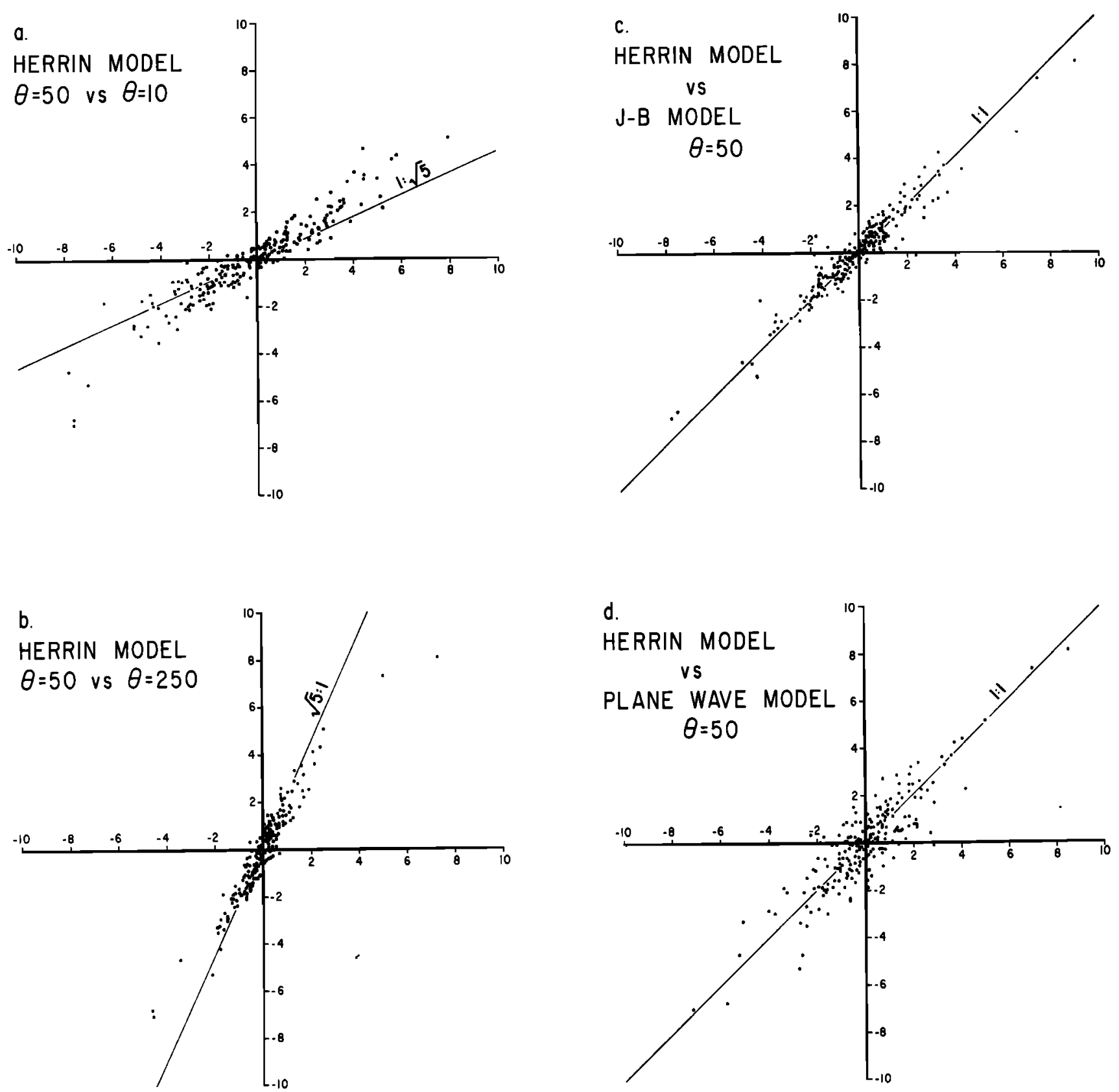

damped least squares solution may be investigated by using the resolution and covariance estimates given by (4) and (5). Resolution of the velocity perturbation for a particular block correlates positively with the number of rays passing through the block and with its location in the model. The best resolution was found for blocks with many observations from widely varying azimuths. This condition is met primarily in the central region of the upper three layers (Figure 8). Resolution for blocks with $R_{t} \geq 0.5$ averages $0.71,0.68$, and 0.63 in layers 1 , 2 , and 3 , respectively. Resolution, which degrades rapidly in the lower two layers of this model, could be improved by decreasing the damping constant $\theta$. However, models with adequate resolution for these deepest layers $(\theta=10)$ have unacceptable standard errors. Consideration of a row of the resolution matrix for specific blocks reveals the way in which the solution for the block depends upon the solution for other

blocks (Figure 9). Coupling of the solution between blocks in the same layer through negative weights is always present and occurs because the average layer velocity is indeterminate [ $A k i$ et al., 1977]. Vertical smoothing presents a more serious problem than the averaging with negative weights within the same layer. The degree of vertical smoothing varies considerably as a function of both position in the model and value of the diagonal resolution element $R_{t}$. In general, vertical smoothing follows the inclined ray paths through the model and is most serious for peripheral blocks with inadequate cross-firing of ray paths.

Standard error estimates for the solution are readily obtained by using (5). The estimated error for the $i$ th element of $\hat{m}$ is

$$
\Delta \hat{m}=C_{i i^{1 / 2}}
$$


Representing $G$ by its normalized eigenvectors $V$ and corresponding eigenvalues $L$ we may write $(4)$ and (5) as

and

$$
R=V\left(\frac{L}{L+\theta 1}\right) V^{T}
$$

$$
C=\sigma_{d}{ }^{2} \mathrm{~V}\left[\frac{\mathrm{L}}{(\mathrm{L}+\theta \mid)^{2}}\right] \mathrm{V}^{T}
$$

In the diagonal basis of $G$, within which $V^{\prime}=\mathrm{I}$, the resolution and covariance matrices are diagonal with elements



MANTLE
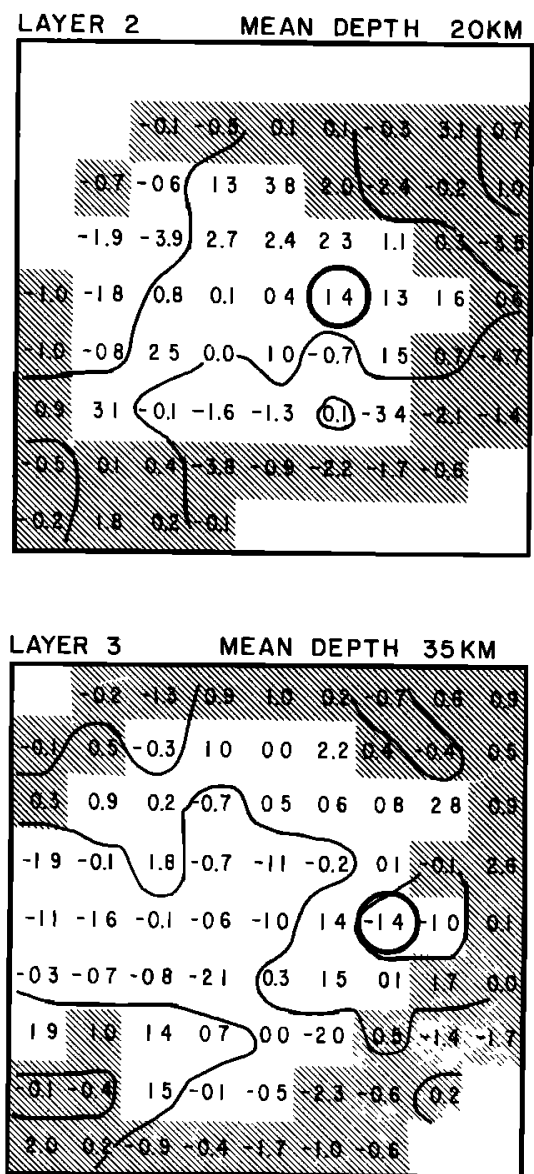

$$
\begin{gathered}
R_{u i^{\prime}}=\frac{L_{l}}{L_{l}+\theta} \\
\vdots \\
C_{i i^{\prime}}=\stackrel{\therefore}{\sigma_{d d}^{2} \frac{L_{l}}{\left(L_{l}+\theta\right)^{2}}}
\end{gathered}
$$

Eliminating $L_{l}$ gives an expression for $C^{\prime}$ in terms of $R^{\prime}, \sigma_{d}$, and $\theta$ :

$$
C_{u i^{\prime}}=\sigma_{d}^{2} \frac{R_{u}^{\prime}\left(1-R_{i i}^{\prime}\right)}{\theta}
$$

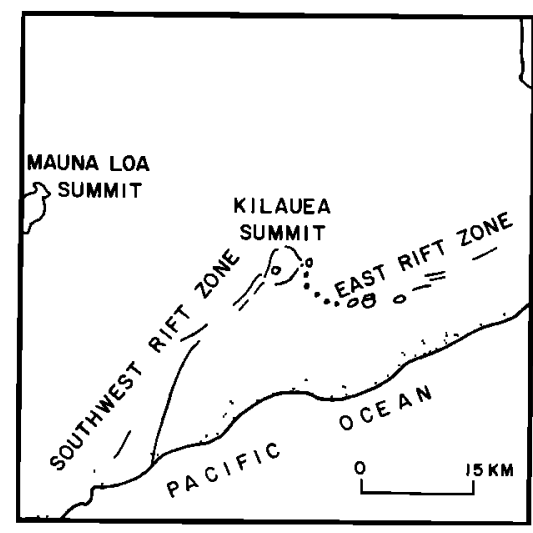

LAYERS
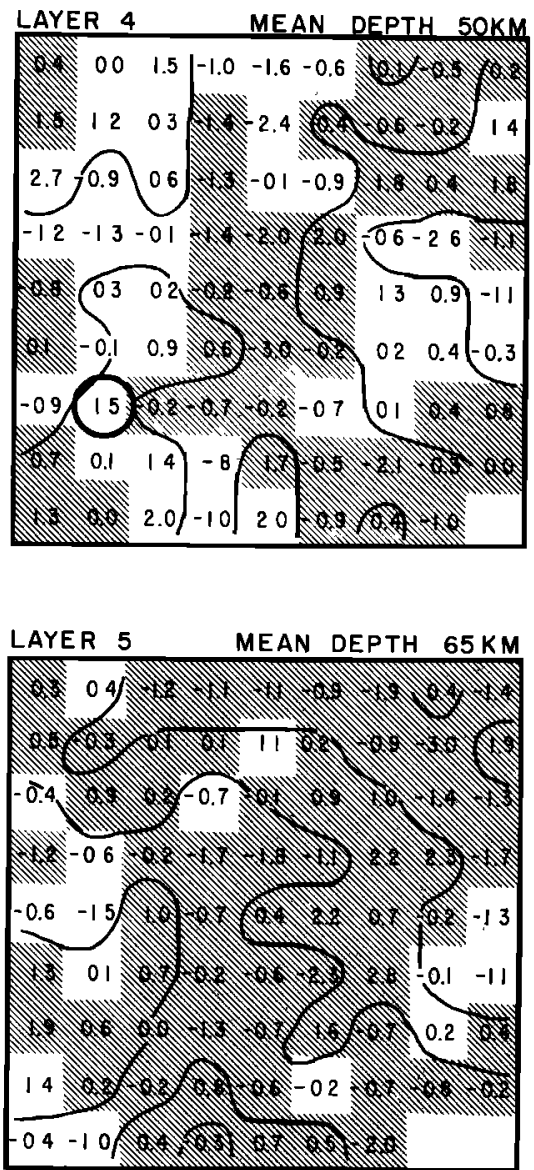

Fig. 8. Laterally varying crust and mantle structure shown as a percent velocity variation. Herrin residuals with $\theta=50$ were used in the inversion. Solution elements with a resolution diagonal element of less than 0.5 are shaded. Portions of the full resolution matrix for circled elements appear in Figure 9. Midlayer depth is indicated. 
PARTS OF RESOLUTION MATRIX

\begin{tabular}{|c|c|c|c|c|c|}
\hline & a. $\hat{m}=7.7 \pm .4 \%$ & b. $\hat{m}=1.4 \pm .5 \%$ & c. $\hat{m}=-1.4 \pm .5 \%$ & d. $\hat{n}=-2.7 \pm .5 \%$ & e. $\mathrm{m}=1.5 \pm .5 \%$ \\
\hline I & $\mid \begin{array}{lllll}-2 & & & -3 \\
-3 & -3 & 0 & & -4 \\
-3 & -6 & 05 & -4 \\
-4 & -5 & -5 & -3 & -3 \\
-3 & -2 & -4 & -3 & -1 \\
\end{array}$ & $\begin{array}{ccccc}0 & & & & -1 \\
-1 & -1 & 0 & & -1 \\
1 & 3 & 5 & 1 & \\
0 & 2 & 3 & 0 & 0 \\
0 & 0 & 0 & -1 & 0 \\
\end{array}$ & $\begin{array}{|ccccc|} & & & 0 \\
0 & 0 & & -1 & 0 \\
1 & 0 & 0 & & \\
1 & -1 & 0 & 2 & -1 \\
0 & 0 & -1 & 0 & \\
\end{array}$ & \begin{tabular}{llll|}
-2 & -3 & -2 & -2 \\
-3 & -5 & -3 & -3 \\
-4 & 74 & -4 & -3 \\
-3 & -3 & -3 & -2 \\
-1 & -2 & \\
\end{tabular} & \begin{tabular}{rrrr|}
1 & 0 & -1 & 1 \\
-1 & -1 & -2 & -1 \\
-1 & -1 & 3 & 0 \\
1 & 0 & & \\
-1 & 0 & & \\
\end{tabular} \\
\hline 2 & $\begin{array}{|ccccc|}0 & 0 & 2 & -1 & 0 \\
1 & 1 & 2 & 4 & 0 \\
0 & 3 & 5 & 5 & 0 \\
0 & 1 & 1 & 0 & 0 \\
0 & 0 & -1 & 0 & 0 \\
\end{array}$ & \begin{tabular}{lllll|}
-1 & -1 & -1 & -1 & 0 \\
-3 & -5 & -4 & -3 & 0 \\
-3 & -6 & 77 & -7 & -2 \\
-2 & -3 & -6 & -3 & -1 \\
-1 & -2 & -1 & -1 & -1 \\
\end{tabular} & $\begin{array}{|ccccc|}-1 & 0 & 0 & 0 & -2 \\
-1 & -1 & 1 & 0 & -1 \\
0 & 9 & 3 & 1 & 0 \\
0 & 3 & 3 & -1 & -1 \\
0 & 0 & -1 & -2 & 0 \\
\end{array}$ & $\begin{array}{|ccccc|}0 & -1 & 2 & 0 & -1 \\
1 & 6 & 3 & 2 & 0 \\
0 & 6 & 4 & 4 & 0 \\
0 & 2 & 0 & 0 & 1 \\
0 & -1 & -1 & & \\
\end{array}$ & $\begin{array}{rrrrr}0 & -1 & 3 & 0 & 0 \\
-1 & 1 & 1 & 3 & 1 \\
0 & 0 & -1 & 2 & 1 \\
0 & 0 & 0 & -1 & 0 \\
-1 & 0 & 0 & 0 & \\
-1\end{array}$ \\
\hline 3 & $\begin{array}{|ccccc|}1 & 2 & 0 & 0 & 2 \\
2 & 0 & -1 & -1 & 4 \\
1 & 0 & -1 & 0 & 2 \\
0 & 0 & -1 & 0 & 0 \\
0 & 2 & 0 & 0 & 0 \\
\end{array}$ & {$\left[\begin{array}{ccccc}0 & -1 & 0 & -1 & -1 \\
-2 & 4 & 4 & 8 & -1 \\
-1 & 3 & 2 & 9 & 1 \\
0 & 0 & -1 & 2 & 0 \\
-1 & -1 & -1 & 0 & 0 \\
\end{array}\right.$} & $\begin{array}{|ccccc|}0 & 0 & -2 & -2 & 0 \\
-3 & -4 & -7 & -3 & -2 \\
-2 & -4 & 67 & -5 & -1 \\
-1 & -4 & -5 & -2 & -1 \\
-1 & -1 & -1 & 0 & -1 \\
\end{array}$ & $\begin{array}{|ccccc|}3 & 0 & 1 & 0 & 2 \\
0 & 0 & 0 & 1 & 0 \\
2 & -1 & 0 & 1 & 2 \\
-1 & 0 & 0 & 1 & 1 \\
1 & 0 & 0 & 0 & 0 \\
\end{array}$ & $\begin{array}{|ccccc|}-1 & 0 & 0 & 0 & 0 \\
0 & 3 & 7 & 1 & 0 \\
-1 & 1 & 7 & -1 & -1 \\
0 & -1 & -1 & -1 & -1 \\
0 & 0 & -1 & 0 & -1 \\
\end{array}$ \\
\hline 4 & \begin{tabular}{ccccc|}
1 & 0 & 0 & 0 & 0 \\
1 & -1 & -1 & 0 & 0 \\
-1 & -1 & 0 & 0 & 1 \\
0 & -1 & -1 & 0 & 0 \\
0 & 0 & -1 & 0 & 1 \\
\end{tabular} & \begin{tabular}{rrrrr|}
2 & 0 & 1 & 0 & 1 \\
2 & 0 & -1 & 0 & -1 \\
2 & 0 & 0 & 0 & 4 \\
0 & 1 & 0 & 1 & 0 \\
0 & 0 & 1 & 0 & -1 \\
\end{tabular} & $\begin{array}{|ccccc|}0 & 0 & 1 & -1 & -2 \\
0 & 1 & 3 & 7 & 3 \\
0 & 0 & 2 & 15 & 2 \\
0 & -1 & 1 & -1 & -1 \\
-1 & 0 & -1 & 0 & -1 \\
\end{array}$ & $\begin{array}{|ccccc|}0 & 1 & 0 & 0 & -1 \\
0 & 0 & 0 & 1 & 0 \\
0 & -1 & 1 & 0 & 2 \\
-1 & 0 & 0 & 0 & 3 \\
-1 & 0 & -1 & 0 & 0 \\
\end{array}$ & $\begin{array}{|ccccc|}0 & -2 & -1 & 0 & 0 \\
-3 & -8 & -3 & -1 & 0 \\
-6 & 66 & -3 & 0 & 0 \\
-4 & -10 & -3 & -1 & 0 \\
-1 & -2 & -2 & -1 & -1 \\
\end{array}$ \\
\hline 5 & $\begin{array}{|ccccc|}0 & 1 & -1 & -1 & 0 \\
-1 & -1 & 0 & 0 & 0 \\
0 & -1 & 0 & -1 & 0 \\
0 & 0 & 0 & 0 & 1 \\
-1 & 0 & 0 & 0 & 0 \\
\end{array}$ & \begin{tabular}{|lllll}
0 & 0 & 0 & -1 & 0 \\
0 & 0 & 0 & -1 & 3 \\
0 & 0 & 0 & 0 & 1 \\
0 & 0 & 0 & 0 & 2 \\
1 & 0 & 0 & 0 & 0 \\
\end{tabular} & $\begin{array}{|rrrrr|}0 & 0 & 0 & -1 & 1 \\
3 & 0 & 1 & 1 & 0 \\
0 & 0 & 1 & 2 & 5 \\
0 & 0 & 0 & -1 & 2 \\
0 & 2 & 0 & -1 & 0 \\
\end{array}$ & \begin{tabular}{lllll|} 
& 0 & 0 & 0 & 0 \\
0 & 0 & 0 & 0 & 1 \\
0 & 0 & 1 & 0 & 0 \\
0 & 0 & 0 & 0 & 3 \\
0 & 0 & 0 & 0 & 0
\end{tabular} & {$\left[\begin{array}{ccccc}-1 & -1 & 0 & 0 & 0 \\
-1 & -1 & -1 & 0 & 0 \\
9 & 1 & 0 & 0 & 0 \\
12 & 2 & 0 & 0 & 0 \\
0 & -1 & 0 & -1 & 0 \\
0 & -1 & -1\end{array}\right.$} \\
\hline
\end{tabular}

Fig. 9. Selected elements of resolution matrix in percent for model parameters with solution value $\dot{m}$ circled in Figure 8 . Portion of resolution matrix displayed for each parameter is shown in the layer block format of Figure 8. Small squares enclose diagonal elements.

Since this expression takes on its maximum value when $R_{u}{ }^{\prime}=$ 0.5 and goes to zero as $R_{i t^{\prime}} \rightarrow 0$ or 1 ,

$$
C_{l i}{ }^{\prime} \leq \sigma_{d}{ }^{2} / 4 \theta
$$

Back transformation of (6) into the model basis leads to a useful upper bound for the standard errors of $\hat{m}$.

$$
\begin{gathered}
C=V C^{\prime} V^{T} \\
\left|C_{i j}\right| \leq\left|\mathrm{V}\left(\sigma_{d}{ }^{2} / 4 \theta\right) I V^{T}\right| \leq\left(\sigma_{d}{ }^{2} / 4 \theta\right)\left|V^{T}\right|
\end{gathered}
$$

and

$$
C_{u} \leq \sigma_{d}^{2} / 4 \theta
$$

since $\left(V V^{T}\right)_{a} \leq 1$. Estimated errors in the solution are thereby bounded by

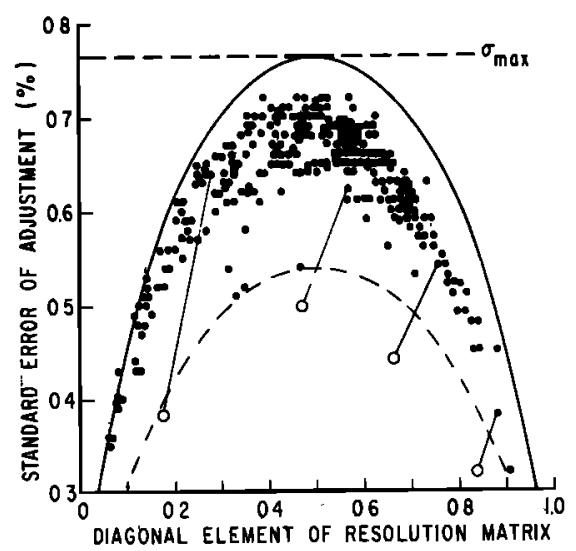

Fig. 10. Solution standard error as a function of diagonal element of resolution matrix. Horizontal line is exact bound on error for $\sigma_{t}=$ $0.108 \mathrm{~s}$. Curved line is the form of the relation in the diagonal basis of $G$. Open circles and connecting lines illustrate the trade off between resolution and error when the damping is doubled. Dashed curve is the form of the relation in the diagonal basis of $G$ for the solution with increased damping.

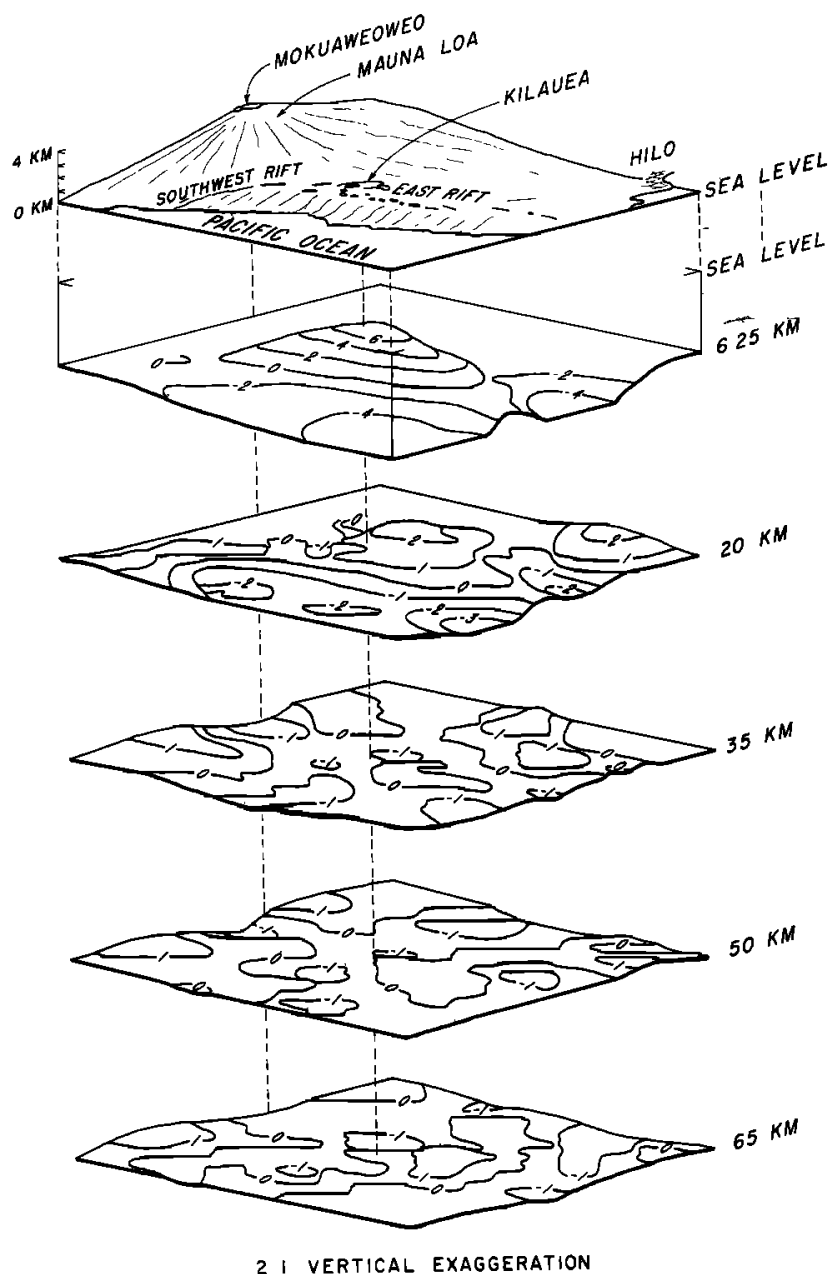

Fig. 11. Perspective view of smoothed velocity perturbations displayed as a raised relief surface. Compressional wave velocity contoured at $2 \%$ intervals in crust and $1 \%$ intervals in mantle.

$$
\Delta \hat{m}_{i} \leq \frac{\sigma_{d}}{2(\theta)^{1 / 2}}
$$

This error bound blows up in the limit as $\theta \rightarrow 0$, which is precisely the case in classical least squares when zero eigenvalues are present in $G$. For the case in which $\theta=50$ and $\sigma_{d}=$ $0.11 \mathrm{~s}$, the maximum error is $0.77 \%$.

An interesting relationship between the resolution matrix and the standard error of the solution was found for this problem. As can be seen from Figure 10, standard errors plotted as a function of the diagonal element of the resolution matrix are clearly bound by (7) and are closely approximated by

$$
\Delta \hat{m}_{t} \doteq \sigma_{d}\left[\frac{R_{u}\left(1-R_{t i}\right)}{\theta}\right]^{1 / 2}
$$

which is the exact relation between standard error and resolution in the diagonal basis of $G$. The maximum error occurs for blocks with $R_{i t}=0.5$ and goes to zero as $R_{i l}$ goes to zero or one. Solution stability for model elements with $R_{t t}<0.5$ is achieved by heavily damping the solution. For this reason we choose to consider only blocks with $R_{l i} \geq 0.5$ in the discussion below. The trade off between resolution and stability for individual blocks is also illustrated in Figure 10 for a solution with the damping doubled. 
Estimation of the uncertainty in the smoothed model (Figure 11 ) is somewhat subjective, since (5) cannot be applied directly. However, by taking the spatial average of two distinct solutions we are in effect trading resolution length for greater stability. For the smoothed model we estimate that velocity fluctuations exceeding $1 \%$ are significant.

\section{Lateral Crust and UpPer Mantle Structure}

Crustal structure estimated for the volcano agrees well with the structure determined by refraction studies. High velocities clearly delineate both the summit complex and its two radial rift zones. Mean crustal velocities of the nonrift flank fall $11-17 \%$ below the mean velocity of the summit (central element in Figure 8). These values agree well with the $15 \%$ velocity contrast between the summit and southeast coast of the island indicated by Hill's [1969] refraction interpretations. Positive velocity perturbations within the rift zones indicate the presence of a high-velocity core formed of a complex of dike swarms, by analogy with older, dissected Hawaiian volcanoes [Wentworth and Jones, 1940]. Velocities determined for the triangular region lying between the rift zones and the Hilina Pali fault system on the south are similar to those found along the rifts and at the summit. The block model element immediately south of the caldera (Figure 8 ) contains neither segments of the rift zone nor eruptive vents of the summit complex and is overlain largely by prehistoric flows [Peterson, 1967; Walker, 1969]. The observation that inflation centers of recent eruptions locate to the south of the caldera [Moore and Krivoy, 1964; Fiske and Kinoshita, 1969] suggests the possibility that this region may be intruded by dikes and sills associated with either contemporary or prehistoric magma chambers.

No evidence for shallow magma chambers in the crust exists in the models of Figures 8 and 11, for such chambers, if present, would be marked by low-velocity zones. This negative result can be attributed to the large block size and long $P$ wave wavelength relative to the dimension of the magma reservoirs $(\sim 1 \mathrm{~km})$ whose presence is well established [Dieterich and Decker, 1975]. Clearly, model results for the crust and deeper layers must be interpreted in terms of average physical properties; they do not resolve smaller-scale structures with stronger velocity contrasts.

Mantle structure for the inverse solution is more homogeneous than that found for the crust. Perturbations for layers 2 and 3 average $1.5 \%$ in contrast to the $4.5 \%$ average change for the crust. Reduction of the average resolution matrix diagonal element by about $10 \%$ may, in part, explain this apparent decrease in heterogeneity with increasing depth. To test performance of the model in the mantle, travel time residuals for a simple structure (embedded sphere with a linear radial velocity gradient [Menke, 1976]) computed by using the same source to receiver ray paths as were used in the inversion of Figure 8 and a comparable level of random errors were inverted. Results indicate that velocity contrasts as small as $2 \%$ are underestimated by about $30 \%$ when $R_{u}$ falls below about 0.6 . Solutions for elements corresponding to homogeneous regions within the synthetic model are all uniformly smaller than the error estimate given by (7).

Discussion of mantle structure divides naturally between the uppermost mantle, lying immediately below the Mohorovicic discontinuity, and deeper structures, lying below about $30 \mathrm{~km}$. In the uppermost mantle (layer 2 of Figure 8 ), velocity perturbations generally mirror the structure of the crust, a broad, high-velocity core underlying the central regions of the volcano and lower velocities appearing on the periphery. The highest velocities within layer 2 are displaced $10 \mathrm{~km}$ north of the caldera; directly beneath the caldera, velocities are more normal. An elongate velocity high extending southwest of the summit suggests some manifestation of the southwest rift in the uppermost mantle. Degraded resolution through coupling of the solution for these blocks to the crustal layer makes a unique interpretation impossible. Clear evidence for a tabular high-velocity zone corresponding to the east rift is absent despite adequate resolution.

Structure of the mantle below about $30 \mathrm{~km}$ has a vertical continuity through the three basal layers of the model. Low velocities appear beneath the summits of Mauna Loa and Kilauea, from where they extend to the southeast. High velocities occupy the southwest corner of the model and an irregular zone lying generally to the east of Kilauea's caldera. Heavy damping and vertical smoothing of the solution in the two deepest layers make a more detailed interpretation undesirable.

\section{COMPARISON WITH Gravity}

The origin of the areal variations in elastic wave velocity within the volcanic pile most probably lies in the degree to which flaws-fractures, cracks, and pores-permeate the crustal rocks. Because tholeiitic basalts of very uniform composition [Wright, 1971] form the entire volcanic edifice, both shield and rift, a simple model relating density to velocity provides a straightforward means for comparison of the three-dimensional velocity structure with the Bouguer gravity anomaly over Kilauea.

Sato [1952] has shown that the change in $V_{p}$ caused by the presence of fluid-filled spherical inclusions in an otherwise homogeneous elastic solid is given by

$$
\begin{aligned}
& \frac{V_{p}}{V_{p_{0}}}=1-\frac{\eta}{2}\left[\frac{(1-\beta)(1+\nu)}{2(1-2 \nu)+\beta(1+\nu)}\right. \\
& \left.+10 \frac{(1-2 \nu)}{(7-5 \nu)}-(1-\nu)\right]
\end{aligned}
$$

where $V_{p_{0}}$ is the velocity of the matrix, $\eta$ is the porosity, $\nu$ is Poisson's ratio, $\beta$ is the compressibility ratio of the matrix to the pore fluid, and $D$ is the density ratio of the fluid to the matrix. The corresponding density contrast is given by

$$
\rho-\rho_{0}=\eta \rho_{0}(1-D)
$$

Although modeling the effect of cavities by spherical holes is simplistic, it closely approximates the effect of roughly equidimensional pores. Cracks or other low aspect ratio cavities, undoubtedly present, will result in an overestimation of the density contrast for a given velocity contrast when (9) and (10) are used [Walsh, 1965]. Variations in velocity due to intrinsic differences in the mineralogy of the matrix will similarly lead to an overestimation of the density contrast. Sato's model thus gives an upper bound on the density contrast.

Below the shallow water table the entire crust of Kilauea is probably saturated [Stearns and Macdonald, 1946], and water is considered to be the pore fluid in calculations for the crustal layer. Velocity variations in the mantle are assumed to be due to inclusions of tholeiitic magma in an olivine-rich peridotic mantle [Jackson and Wright, 1970]. Density and compressibility data for basalt and peridotite from Birch [1966] and data for tholeiitic magma, after correction to mantle pressures, 
TABLE 3. Compressibility and Density of Materials Used in Calculation of Density Contrast From Velocity Data

\begin{tabular}{llccc}
\hline & \multicolumn{1}{c}{ Material } & $\begin{array}{c}\text { Compressibility, } \\
\mathrm{cm}^{2} / \text { dyn }\end{array}$ & $\begin{array}{c}\text { Density, } \\
\mathrm{g} / \mathrm{cm}^{3}\end{array}$ & $\begin{array}{c}P \text { Velocity, } \\
\mathrm{km} / \mathrm{s}\end{array}$ \\
\hline Crustal matrix & basalt & $1.5 \times 10^{-12}$ & 2.9 & 6.4 \\
Crustal pore fluid & water & $4.5 \times 10^{-11}$ & 1.0 & 1.5 \\
Mantle matrix & dunite & $8 \times 10^{-13}$ & 3.25 & 8.2 \\
Mantle pore fluid & tholeitic magma & $6 \times 10^{-12}$ & $2.76^{*}$ & 2.5 \\
\hline
\end{tabular}

*At 30 kbars.

from Murase and McBirney [1973] (Table 3) were used in the computation of density contrasts corresponding to the velocity model of Figure 8. For each block element of the model the porosity $\eta$ needed to produce the observed velocity contrast was found by using (9) with $\nu=0.25$. The corresponding density contrast was found by using (10). Bouguer gravity anomalies computed for the entire block model by using the density contrasts obtained for each model element and the formulation for the gravitational attraction of a right rectangular prism of Nagy [1966] give the anomaly map of Figure 12. The computed anomalies agree well in both form and amplitude with the Bouguer gravity map of Kinoshita et al. [1963]. This agreement further supports the validity of the crustal velocity model. Contributions to the gravity anomaly map from the mantle do not influence the fit of the model and are unconfirmed by this test.

\section{Discussion}

Perhaps the single most striking feature of upper mantle structure (Figures 8 and 11) is the absence of strong lateral variations. The upper mantle underlying Kilauea is surprisingly homogeneous, having only minor velocity fluctuations about the nominal velocity of $8.1 \mathrm{~km} / \mathrm{s}$. These results contrast sharply with Iyer's [1973] results from Yellowstone, where teleseismic travel time observations clearly indicate a substantial (5-10\%) low-velocity zone beneath Yellowstone caldera extending to a depth of at least $75 \mathrm{~km}$. Synthetic model results show that were such strong lateral contrasts present beneath Kilauea, even in the deepest regions of the model of Figure 8, they would be recovered by our data. Absence of strong velocity contrasts implies either that pronounced lowvelocity zones with lateral dimensions larger than about $10 \mathrm{~km}$ are absent or that the low-velocity zone encompasses a region at least as large as the $70-\mathrm{km}$-wide model.

The relatively minor lateral heterogeneities present beneath Kilauea may arise through several distinct physical mechanisms, including petrologic variations, regional variations in stress and temperature, and the presence of magma. Of these mechanisms, temperature gradients and magmatic concentrations undoubtedly exist deep within the volcano. Temperature acting alone has been estimated by Birch [1958] to give rise to a $1 \%$ decrease in velocity for a $250^{\circ} \mathrm{C}$ elevation in temperature, a thermal contrast expectable between zones containing partial melt and zones devoid of melt. Evaluation of the elastic effect of partial melt upon $V_{p}$ is dependent upon the volume fraction of melt, the moduli and densities of the liquid and solid phases, and the geometric configuration of the melt within the body. High aspect ratio inclusions, as noted above, may be satisfactorily modeled as spheres. This model gives an upper bound on the melt fraction required to produce a given velocity change. If (9) and Table 3 are used, a $1.2 \%$ volume concentration of magma reduces $V_{p}$ by at least $1 \%$ in relation to mantle of the same configuration but devoid of melt. Although a $1.2 \%$ melt volume fraction may seem to be an insignificant quantity, this concentration in one block model element represents $10 \mathrm{~km}^{3}$ of magma, enough to supply Kilauea for 100 years at the current supply rate of $10^{8} \mathrm{~m}^{3} / \mathrm{yr}$ [Swanson, 1972]. Lateral variations in
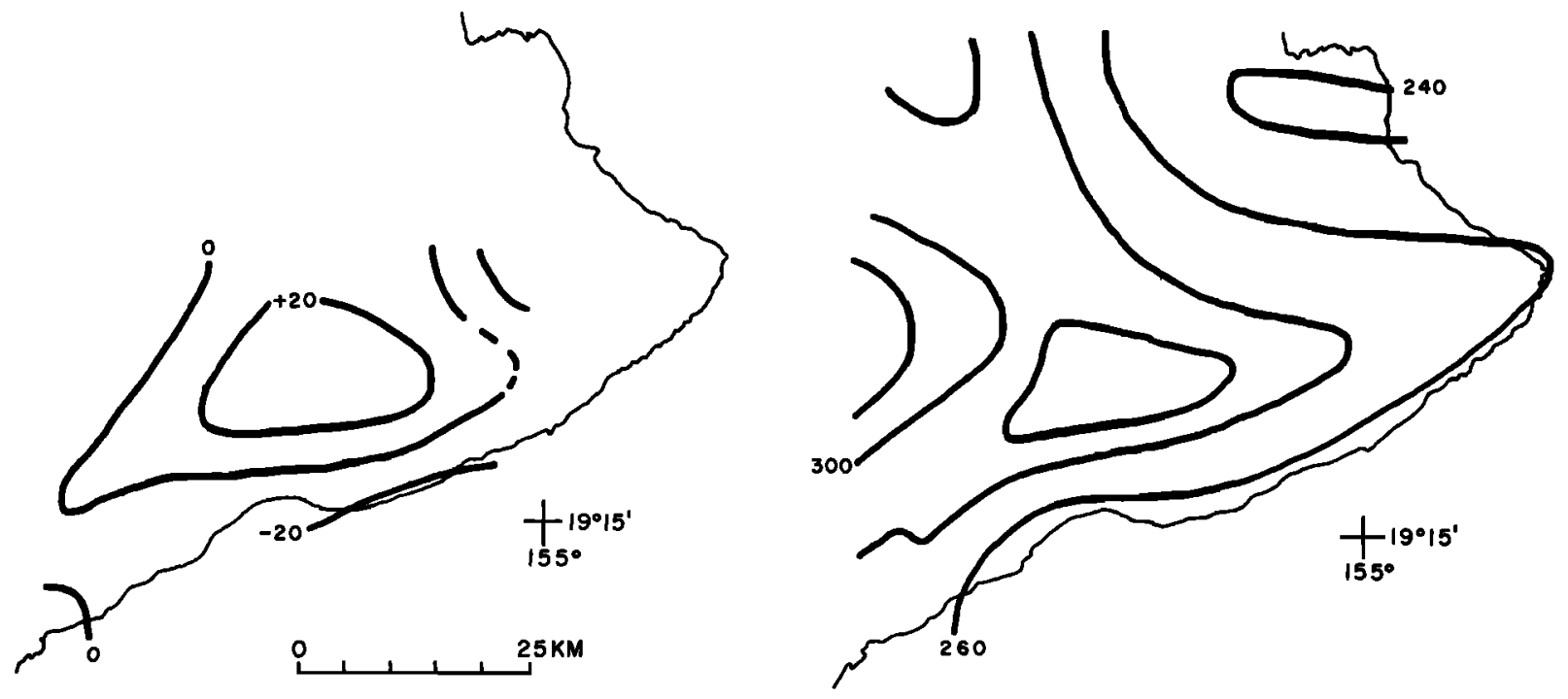

Fig. 12. Comparison of Bouguer gravity anomalies (left) computed by using the velocity model and (right) observed by Kinoshita et al. [1963]. Contour interval is $20 \mathrm{mGal}$. 

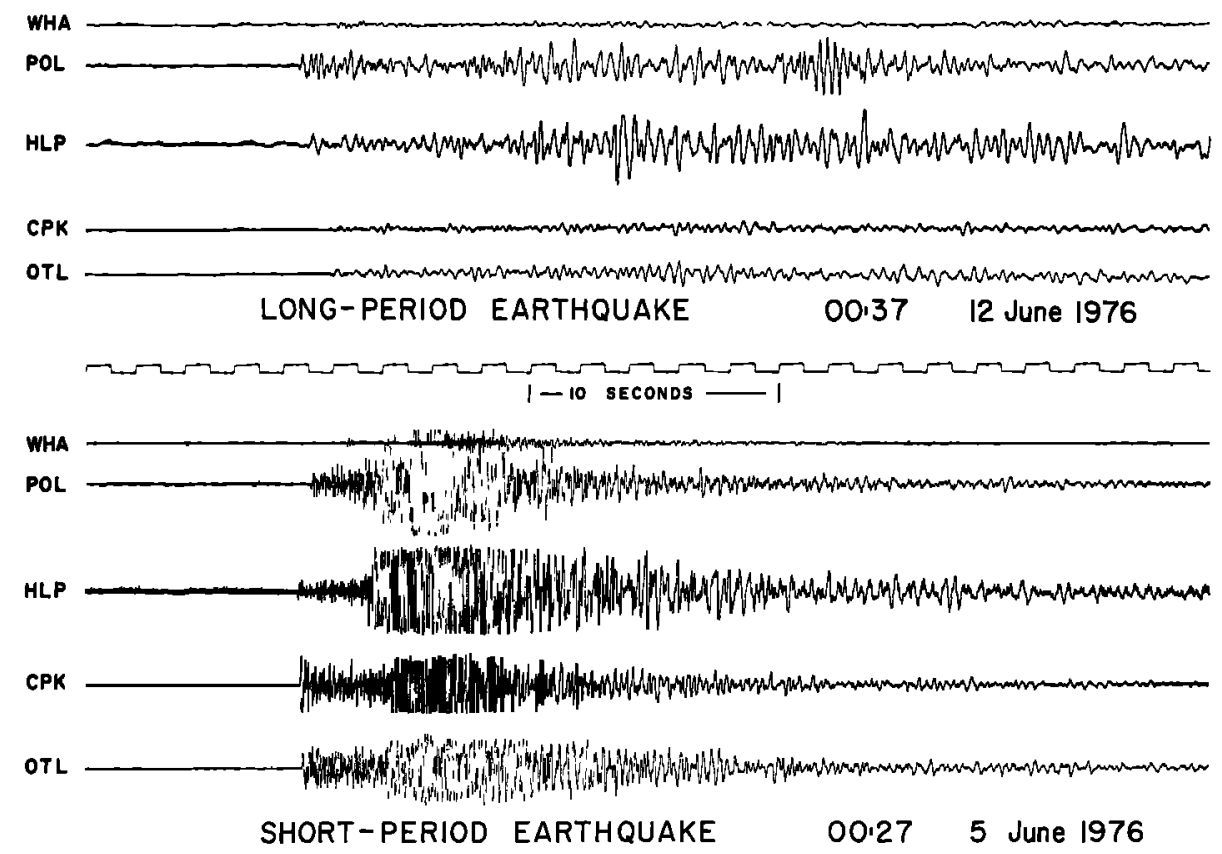

Fig. 13. Seismograms for long-period type earthquake and short-period type earthquake.

$V_{p}$ arising from variations in pressure are probably insignificant in the mantle beneath Kilauea, as pressure changes exceeding $5 \mathrm{kbars}$ are needed to produce a $1 \%$ velocity change. Differences in velocity caused by variations in mineralogy or anisotropy may be important and cannot be ruled out as the source of observed velocity fluctuations in the mantle. However, the effects of temperature and magma can be more readily related to processes active within the volcano.

The features of mantle velocity structure below about $30-\mathrm{km}$ depth which correspond most closely with surficial features of Kilauea and Mauna Loa are the zones of below-average velocity vertically aligned beneath the summits of the two volcanoes (Figure 11). Existence of low-velocity mantle underlying the volcanic summits is not surprising. Intuitively, one expects that shield volcanoes are built up of magmas that rise from deep within the upper mantle through conduits connecting magmatic source with the summit complex [e.g., Eaton, 1962; Jackson and Wright, 1970]. Low-velocity mantle also extends to the south of Kilauea's summit (Figure 11). Although it is speculative in nature, the hypothesis that hot rock containing partial melt is responsible for the low-velocity mantle is supported by independent seismic evidence.

Seismic disturbances from within the mantle underlying the island of Hawaii and its offshore flank characteristically take three forms: short-period earthquakes, long-period earthquakes, and volcanic tremor [Koyanagi, 1968]. All three are restricted to depths of less than $60-65 \mathrm{~km}$ and ultimately originate as a by-product of volcanic processes [Eaton, 1962]. Short-period mantle earthquakes occur widely beneath the island of Hawaii and are similar in character to earthquakes occurring at comparable depths recorded elsewhere in the world. The strain energy they release may result from a variety of mechanisms, including the load of the island on the lithosphere, volumetric strains associated with partial melting of the mantle, forceful passage of magma through conduits, and, perhaps, release of long-wavelength stresses within the Pacific plate itself. Tremor, on the other hand, is directly related to the movement of magma within the volcano [Shimozuru et al., 1966]. Long-period earthquakes accompany outbursts of tremor originating deep within the mantle. They are characterized by a substantially lower frequency content $(2-5 \mathrm{~Hz})$ than the more common short-period earthquakes (Figure 13). Hypocentral coordinates for these long-period events provide a powerful tool for determining the locus of tremor sources within the mantle, thereby outlining regions deep within the substructure of the volcano containing mobile concentrations of magma. Deep tremor and time-related long-period earthquakes are not restricted to the well-known 55- to 60-km-deep source beneath Kilauea's summit [Eaton, 1962] but also emanate from sources at considerable lateral distance from the summit. Tremor has yet to be documented from sources below about $60 \mathrm{~km}$, and like the mantle earthquakes it rarely occurs below $50 \mathrm{~km}$.

The distribution of mantle earthquakes with focal depths between 27.5 and $42.5 \mathrm{~km}$ for the 12-month period from July 1971 to June 1972 [Koyanagi et al., 1974; Okamura et al., 1974; Onouye et al., 1974; Yamamoto et al., 1974] shown in Figure 14 is representative of the earthquake pattern for the preceding decade. The foci of short-period earthquakes (open circles) concentrate below the summit of Kilauea and in a broad zone off the south coast of the island. Tremor-related long-period earthquakes (denoted by solid circles in Figure 14) concentrate in an elliptical source region $35 \mathrm{~km}$ southwest of Kilauea. This source region has, on the basis of these time-related earthquakes, been a persistent tremor source during the past decade. Visually, the epicenters correlate with zones of below average velocity, especially beneath Kilauea and in the offshore zone to the south. Mantle earthquakes near Mauna Loa are comparatively rare; none occurred during this 12-month period. Deep earthquake activity $(30-50 \mathrm{~km})$ prior to the July 1975 eruption of Mauna Loa was, however, concentrated in the low-velocity regions below the summit [Koyanagi et al., 1975].

Consideration of the lateral variation in mantle velocity structure together with the distribution of mantle earthquakes and tremor sources leads us to suggest the following hypotheses:

1. In the depth range of 30 to at least $60 \mathrm{~km}$, magma is 


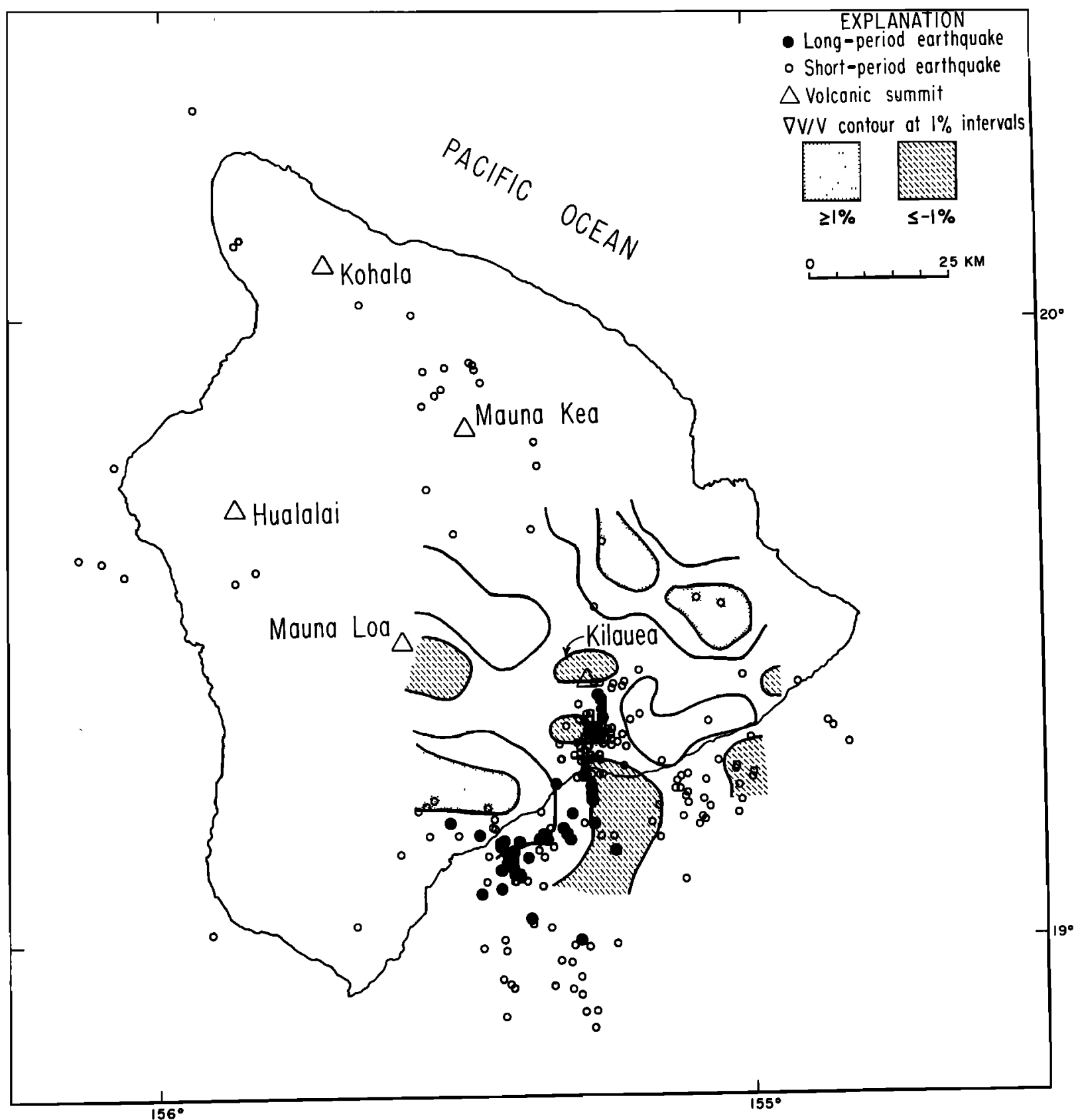

Fig. 14. Epicenters of mantle earthquakes at depths of $27.5-42.5 \mathrm{~km}$ occurring between July 1971 and June 1972. Percent velocity variations from layer 3 of smoothed model. Triangles locate volcanic summits

supplied to the central summits of the volcanoes by a laterally extensive conduit system.

2. Magma may be produced from the mantle in this depth range over a broad area in addition to being in transit through the upper mantle from deeper-seated sources.

3. The center of contemporary magmatic production and/or upwelling from deeper sources extends well to the south of the active volcanic vents.

The occurrence of tremor from sources laterally well'removed from the summits of either Kilauea or Mauna Loa attests to the areal distribution of melt within the deeper regions of the volcano. Correlation of tremor sources and mantle earthquakes with low-velocity regions lends support to the hypothesis that the youthful shield volcanoes on Hawaii are underlain by a laterally distributed magma supply system. Refinement of the three-dimensional velocity structure using local mantle earthquakes as sources is planned to clarify further the relation noted here between velocity structure and seismic disturbances in the mantle.

Source depths for magmatic generation have been largely assumed to lie below the deepest earthquakes [Jackson and Wright, 1970; Murata, 1970; Wright, 1971]. Buoyancy forces alone require a column of magma only $40 \mathrm{~km}$ high to reach the summit of Kilauea at $1.2 \mathrm{~km}$ above sea level and $60 \mathrm{~km}$ high to reach Mokuaweoweo atop Mauna Loa at $4.1 \mathrm{~km}$ [Eaton and Murata, 1960; Murata, 1970]. It seems plausible then that tholeiite may be produced from rocks substantially above the deepest earthquakes as well as from greater depths. Whether the source of the magmas lies within the lithosphere or within the asthenosphere, it is clear that the magmatic passageways from source to surface do not have strong seismic velocity expression within the upper half of the Pacific plate. 
Finally, it is noteworthy that the overall distribution of mantle earthquakes at intermediate depths $(25-50 \mathrm{~km})$ is centered south of Kilauea. The concentration of deep, long-period earthquakes and associated deep tremor $35 \mathrm{~km}$ south-southwest of Kilauea caldera (Figure 14) delineates a region of current magmatic movement without obvious temporal association with eruptive processes on either Kilauea or Mauna Loa. This offshore source region may connect to the plumbing system of these volcanoes, or it may represent the locus of a new volcano. The zone falls within the trend of volcanic summits on Hawaii and lies at an epicentral distance from both Kilauea and Mauna Loa that is very nearly equal to the mean distance between adjacent volcanoes on the island.

\section{Conclusions}

Inversion of teleseismic $\boldsymbol{P}$ wave arrival times recorded by seismograph stations located on Kilauea for three-dimensional velocity structure successfully recovers the principal features of volcanic crustal structure. The central summit and radial rift zones are composed of basalts with average velocities that are $11 \%$ to $18 \%$ higher than those of surrounding sections of the shield. These velocity contrasts agree well with results from crustal refraction studies, and when they are related to density through a plausible physical model, they agree well with Bouguer gravity anomalies over the volcano. Large amplitude heterogeneities in the velocity structure are absent in the mantle underlying the volcano, an indication that large volume concentrations of magma are absent to depths of at least $40 \mathrm{~km}$. Fine structure of the mantle below about $30-\mathrm{km}$ depth indicates that low-velocity zones underlie the summits of Kilauea and Mauna Loa and extend south of Kilauea into a broad offshore zone. Correlation of low-velocity regions in the upper mantle with persistent source regions of mantle earthquake and volcanic tremor suggests that the low velocities result from elevation of temperature and presence of partial melt within a laterally connected conduit system that feeds the volcanoes either from sources at comparable depths or from sources deeper within the mantle.

Acknowledgments. One of us (W.L.E.) wishes to thank the staff of the Hawaiian Volcano Observatory, especially Robert Tilling, for their hospitality and assistance during the summer of 1975. John Unger generously made available travel time data that he compiled at HVO. Many helfpul and stimulating discussions with Keiiti Aki and George Zandt are gratefully acknowledged. George Zandt also made available his program for computing three-dimensional gravity anomalies. Nancy Ellsworth and Jane Lamb provided invaluable assistance in preparation of the data and manuscript. We also thank Jerry Eaton, Dave Hill, Raul Madariaga, Tony Shakal, and Dave Hadley for many helpful criticisms and suggestions.

\section{REFERENCES}

Aki, K., A. Christoffersson, and E. S. Husebye, Three-dimensional seismic structure of the lithosphere under Montana Lasa, Bull. Seismol. Soc. Amer., 66, 501-524, 1976.

Aki, K., A. Christoffersson, and E. S. Husebye, Determination of the three-dimensional seismic structure of the lithosphere, J. Geophys. Res., 82, 277-296, 1977.

Birch, F., Interpretation of the seismic structure of the crust in the light of experimental studies of wave velocities in rocks, in Contributions in Geophysics in Honor of Beno Gutenberg, pp. 158-170, Pergamon, New York, 1958.

Birch, F., Compressibility; elastic constants, Handbook of Physical Constants, Geol. Soc. Amer. Mem., 97, 97-103, 1966.

Dieterich, J. H., and R. W. Decker, Finite element modeling of surface deformation associated with volcanism, J. Geophys. Res., 80, 4094-4102, 1975.

Eaton, J. P., Crustal structure and volcanism in Hawaii, in The Crust of the Pacific Basin, Geophys. Monogr. Ser., vol. 6, edited by G. A. Macdonald and H. Kuno, pp. 13-29, AGU, Washington, D. C., 1962.

Eaton, J. P., and K. J. Murata, How volcanoes grow, Science, 132. 925-938, 1960.

Fiske, R. S., and W. T. Kinoshita, Inflation of Kilauea volcano prior to its 1967-1968 eruption, Science, 165, 341-349, 1969.

Franklin, J., Well-posed stochastic extensions of ill-posed linear problems, J. Math. Anal. Appl., 21, 682-716, 1970.

Hill, D. P., Crustal structure of the island of Hawaii from seismic refraction measurements, Bull. Seismol. Soc. Amer., 59, 101-130, 1969.

Husebye, E., A. Christoffersson, K. Aki, and C. Powell, Preliminary results on the 3-dimensional seismic structure of the lithosphere under the USGS central California seismic array, Geophys. J. Roy. Astron. Soc., 46, 319-340, 1976.

Iyer, H. M., Anomalous delays of teleseismic $P$ waves in Yellowstone National Park, Nature, 253. 425-427. 1973.

Jackson, E. D., and T. L. Wright, Xenoliths in the Honolulu volcanic series, Hawaii, J. Petrology. II, 405-430, 1970.

Kinoshita, W. T., H. L. Krivoy, D. R. Mabey, and R. R. MacDonald, Gravity survey of the island of Hawaii, U.S. Geol. Surv. Prof. Pap., 475-C, CI14-C116, 1963.

Koyanagi, R. Y., Earthquakes from common sources beneath Kilauea and Mauna Loa volcanoes in Hawaii from 1962 to 1965, U.S. Geol. Surv. Prof. Pap., 600-C, C120-C125, 1968.

Koyanagi, R. Y., A. T. Okamura, and G. Kojima, Hawaiian Volcano Observ. Sum., 63, 99 pp., 1974.

Koyanagi, R. Y., E. T. Endo, and J. E. Ebisu, Reawakening of Mauna Loa volcano, Hawaii: A preliminary evaluation of seismic evidence, Geophys. Res. Lett., 2, 405-408, 1975.

Lanczos, C., Linear Differential Operators, Chap. 3, 564 pp., Van Nostrand Reinhold, New York, 1961.

Levenberg, K., A method for the solution of certain non-linear problems in least squares, Quart. Appl. Math., 2, 164-168, 1944.

Menke, W. H., Lateral variation of $P$ velocity in the Himalayan crust and upper mantle, M.S. thesis, 72 pp., Mass. Inst. of Technol., Cambridge, 1976.

Mogi, K., Relations between the eruptions of various volcanoes and the deformations of the ground surface around them, Bull. Earthquake Res. Inst. Tokyo Univ., 36, 99-134, 1958.

Moore, J. G., and H. L. Krivoy, The 1962 flank eruption of Kilauea volcano and structure of the east rift zone, J. Geophys. Res., 69 , 2033-2045, 1964.

Murase, T., and A. R. McBirney, Properties of some common igneous rocks and their melts at high temperatures, Geol. Soc. Amer. Bull., 84, 3563-3592, 1973.

Murata, K. J., Tholeiitic basalt magmatism of Kilauea and Mauna Loa volcanoes of Hawaii, Naturwissenshaften, 57, 108-113, 1970.

Nagy, D., The gravitational attraction of a right rectangular prism, Geophysics, 31, 362-371, 1966.

Okamura, A. T., R. Y. Koyanagi, and M. S. Onouye, Hawaiian Volcano Observ. Sum., 64, 83 pp., 1974.

Onouye, M. S., A. T. Okamura, and R. Y. Koyanagi, Hawaiian Volcano Observ. Sum., 65, 53 pp., 1974.

Peterson, D. W., Geologic map of the Kilauea Crater quadrangle, Hawaii, Geol. Quadrangle Map GW-667, U.S. Geol. Surv., Reston, Va., 1967.

Ryall, A., and D. L. Bennett, Crustal structure of southern Hawaii related to volcanic processes in the upper mantle, J. Geophys. Res., 73, 4561-4582, 1968.

Sato, Y., Velocity of elastic waves propagated in media with small holes, Bull. Earthquake Res. Inst. Tokyo Univ., 30, 178-190, 1952.

Shimozuru, D., K. Kamo, and W. T. Kinoshita, Volcanic tremor of Kilauea volcano, Hawaii, during July-December, 1963, Bull. Earthquake Res. Inst. Tokyo Univ., 44, 1093-1133, 1966.

Stearns, H. T., and G. A. Macdonald, Geology and ground-water resources of the island of Hawaii, Hawaii Hydrogr. Div. Bull., 9, $1-362,1946$.

Swanson, D. A., Magma supply rate at Kilauea volcano, 1952-1971, Science, 175, 169-170, 1972.

Swanson, D. A., W. A. Duffield, and R. T. Okamura, Seaward displacement of the south flank of Kilauea volcano (abstract), Eos Trans. $A G U, 52,372,1971$.

Walker, G. W., Geologic map of the Kau desert quadrangle, Hawaii, Geol. Quadrangle Map GQ-827, U.S. Geol. Surv., Reston, Va., 1969. Walsh, J. B., The effect of cracks on the compressibility of rocks, $J$. Geophys. Res., 70, 381-389, 1965. 
Wentworth, C. K., and A. E. Jones, Intrusive rocks of the leeward slope of the Koolau Range, Oahu, J. Geol., 48, 975-1006, 1940 Wilson, J. T., A possible origin of the Hawaiian Islands, Can. J. Phys. $41,863-870,1963$.

Wright, T. L., Chemistry of Kilauea and Mauna Loa lava in space and time, U.S. Geol. Surv. Prof. Pap., 735, 40 pp., 1971.
Yamamoto, A., J. S. Forbes, and M. K. Sako, Hawaiian Volcano Observ. Sum., 66, 43 pp., 1974.

(Received October 7, 1976;
revised June 16, 1977;

revised June 16, 1977;

accepted June 28, 1977.) 